Article

\title{
The Potential of Influenza HA-Specific Immunity in Mitigating Lethality of Postinfluenza Pneumococcal Infections
}

Miriam Klausberger ${ }^{1, *(\mathbb{C})}$, Irina A. Leneva ${ }^{2}$, Irina N. Falynskova ${ }^{2}$, Kirill Vasiliev ${ }^{3}(\mathbb{D}$, Alexander V. Poddubikov $\left.{ }^{4}{ }^{(}\right)$, Claudia Lindner ${ }^{1}$, Nadezhda P. Kartaschova ${ }^{2}$, Oxana A. Svitich ${ }^{2}$, Marina Stukova ${ }^{3}$, Reingard Grabherr ${ }^{1, *}$ and Andrej Egorov ${ }^{2,3}$

1 Department of Biotechnology, University of Natural Resources and Life Sciences (BOKU), 1190 Vienna, Austria; claudia.lindner@evercyte.com

2 Department of Virology, I. Mechnikov Research Institute for Vaccines and Sera, Moscow 105064, Russia; wnyfd385@yandex.ru (I.A.L.); falynskova@mail.ru (I.N.F.); nadezdakartasova10571@gmail.com (N.P.K.); svitichoa@yandex.ru (O.A.S.); aevirol@gmail.com (A.E.)

3 Smorodintsev Research Institute of Influenza, St. Petersburg 197376, Russia; kirillv5@yandex.ru (K.V.); stukova@influenza.spb.ru (M.S.)

4 Department of Microbiology, I. Mechnikov Research Institute for Vaccines and Sera, Moscow 105064, Russia; poddubikov@yandex.ru

* Correspondence: miriam.klausberger@boku.ac.at (M.K.); reingard.grabherr@boku.ac.at (R.G.); Tel.: +43-1-47654-79858 (M.K.); +43-1-47654-79006 (R.G.)

Received: 4 October 2019; Accepted: 11 November 2019; Published: 17 November 2019

Abstract: Influenza virus infections pre-dispose an individual to secondary pneumococcal infections, which represent a serious public health concern. Matching influenza vaccination was demonstrated helpful in preventing postinfluenza bacterial infections and associated illnesses in humans. Yet, the impact of influenza hemagglutinin (HA)-specific immunity alone in this dual-infection scenario remains elusive. In the present study, we assessed the protective effect of neutralizing and non-neutralizing anti-hemagglutinin immunity in a BALB/c influenza-pneumococcus superinfection model. Our immunogens were insect cell-expressed hemagglutinin-Gag virus-like particles that had been differentially-treated for the inactivation of bioprocess-related baculovirus impurities. We evaluated the potential of several formulations to restrain the primary infection with vaccine-matched or -mismatched influenza strains and secondary bacterial replication. In addition, we investigated the effect of anti-HA immunity on the interferon status in mouse lungs prior to bacterial challenge. In our experimental setup, neutralizing anti-HA immunity provided significant but incomplete protection from postinfluenza bacterial superinfection, despite effective control of viral replication. In view of this, it was surprising to observe a survival advantage with non-neutralizing adaptive immunity when using a heterologous viral challenge strain. Our findings suggest that both neutralizing and non-neutralizing anti-HA immunity can reduce disease and mortality caused by postinfluenza pneumococcal infections.

Keywords: Influenza; Streptococcus pneumoniae; secondary bacterial infection; off-target vaccine effects; anti-HA immunity; type I/II interferon; VLP vaccine; baculovirus inactivation

\section{Introduction}

A leading cause of the mortality observed during both seasonal and pandemic influenza outbreaks can be attributed to secondary respiratory infections with bacteria, such as Streptococcus pneumoniae (S. pneumoniae, pneumococcus) [1]. Pneumococcus is a frequent commensal of the human upper 
respiratory tract of healthy individuals, with the highest prevalence (up to $50 \%$ ) in children younger than two years of age [2]. Influenza and pneumococcal infections follow a winter seasonality pattern [3]. This characteristic increases the likelihood for combined or sequential infections, which manifest as more severe illnesses with higher mortality rates than disease caused by either pathogen alone [4]. Murine studies demonstrated that an influenza virus infection increases the susceptibility to subsequent pneumococcal infection and revealed potential mechanisms involved. There is strong evidence that virus-mediated activation of innate immunity plays a decisive role in rendering an influenza-infected individual less capable of mounting a proper immune response towards a secondary bacterial invader [5-9]. In this regard, expression of the innate cytokines type I $(\alpha / \beta)$ and type II $(\gamma)$ interferon (IFN) in response to viral infection can attenuate the phagocytic function of tissue-resident alveolar macrophages (AMs) [10,11] or impair the recruitment of neutrophils [12] and natural killer (NK) cells [13] to the site of infection. Moreover, type I IFNs were associated with the negative regulation of unconventional T cells ( $\gamma \delta \mathrm{T}$ cells) by blocking the expression of cytokines (i.e., interleukin-17A, IL-17A) that are pivotal in initiating effective antibacterial innate immune responses $[5,14]$.

One way to prevent postinfluenza pneumococcal complications would be by means of prophylactical measures against the bacterial pathogen. There are, however, indications that pneumococcal-specific vaccine-induced immunity is not effective in the context of viral-bacterial infections $[15,16]$. In addition, marketed pneumococcal vaccines provide serotype-specific immunity and cover only a fraction (max. 23) out of 98 currently known serotypes [17]. With the widespread introduction of childhood pneumococcal immunization programs vaccine serotypes in circulation have been rapidly replaced by non-vaccine serotypes, which compromises the benefit of implemented programs [18]. There is a limited but growing number of studies available that acknowledge the protective role of influenza vaccination in the context of secondary bacterial infections (SBIs) in the mouse model and in humans [19-22]. Influenza vaccination predominantly focuses on the induction of antibodies towards the head domain of the influenza hemagglutinin (HA). Such antibodies effectively prevent an infection, but the rapid antigenic drift of the protein may render elicited immunity ineffective [23]. Still, mismatched influenza vaccines prime non-neutralizing immunity that do not prevent an infection but can reduce illness and mortality [24-26].

In the present study, we investigated the distinct role of neutralizing and non-neutralizing anti-HA immunity in the protection from postinfluenza pneumococcal disease and mortality in a murine BALB/C superinfection model. We employed different vaccine preparations based on Gag-virus-like particles (Gag-VLPs) containing the influenza HA of A/PR/8/34 (H1N1) that were expressed in insect cells using the baculovirus expression vector system. To abolish potential immune-modulating effects of residual baculovirus (BV) in the preparations, we employed two alternative chemicals ( $\beta$-propiolactone or binary ethylenimine) for viral inactivation. Vaccine efficacy was evaluated after infection with antigenically distinct $\mathrm{H} 1 \mathrm{~N} 1$ viruses followed by a secondary pneumococcal challenge. We tested the effect of immunization on the host IFN response after viral infection and on disease exacerbation after secondary bacterial infection.

\section{Materials and Methods}

\subsection{Ethics Statement}

All animal experiments were conducted in strict accordance with the "Rules for laboratory practice in the Russian Federation" of the Ministry of Health of Russia (23.08.2010 No. 708H) and were approved by the Institutional Animal Care and Use Committee (IACUC) of the I. Mechnikov Research Institute for Vaccines and Sera, Moscow Russia (28/01/2019, No.5). Research staff handling animals were trained in animal care and handling. All efforts were made to minimize animal suffering. 


\subsection{Animals and Cells}

Four-to-six-week old female BALB/c mice were purchased from the Research Center for Biomedical Technology (Andreevka, Moscow, RU). Mice were arbitrarily assigned to study groups, had free access to food and sterilized tap water, and were kept on a 12-h light/dark cycle.

Sf9 (ATCC CRL-1711) and Tnms42 insect cells (a gift from G. Blissard, Boyce Thompson Institute, Ithaca, NY) [27] were routinely propagated in adherent culture in HyClone SFM4 insect cell medium (GE Healthcare, Little Chalfont, UK) at $27^{\circ} \mathrm{C}$ and were expanded in suspension culture for recombinant baculovirus working stock generation or recombinant protein expression, respectively.

Madin-Darby Canine Kidney (MDCK) cells (American Type Culture Collection, Manassas, VA, USA) were grown in minimal essential medium (MEM) supplemented with $10 \%(v / v)$ fetal bovine serum (FBS), $5 \mathrm{mM}$ L-glutamine, $25 \mathrm{mM}$ HEPES, $100 \mathrm{U} / \mathrm{mL}$ penicillin, $100 \mu \mathrm{g} / \mathrm{mL}$ streptomycin sulfate and $100 \mu \mathrm{g} / \mathrm{mL}$ kanamycin sulfate in a humidified atmosphere of $5 \%(v / v) \mathrm{CO}_{2}$.

\subsection{Infectious Agents}

Baculovirus (BV) working stocks were propagated in $S f 9$ cells and titrated by a tissue culture infectious dose $50\left(\mathrm{TCID}_{50}\right)$ assay. Briefly, $S f 9$ cells were seeded into sterile, tissue culture-treated 96-well microplates (Corning Inc., Corning, NY, USA) at 32,000 cells/well in a total volume of $100 \mu \mathrm{L}$. Baculovirus working stocks or HA-Gag VLP preparations were serially five-fold diluted in medium, including antibiotics (dilution range $2.0 \times 10^{-1}-4.1 \times 10^{-9}$ ) in triplicates. Thirty $\mu \mathrm{L}$ of each sample dilution was added to the cells to yield eight replicates per virus dilution. Plates were incubated for five days at $27^{\circ} \mathrm{C}$, and the infection status was assessed on the basis of the expression of an infection reporter, the yellow fluorescent protein (YFP), in infected cells. The viral titer in $\mathrm{TCID}_{50} / \mathrm{mL}$ was calculated using the method of Reed and Muench and was converted into pfu/mL by the Poisson distribution-derived factor 0.69 [28].

Influenza virus A/Puerto Rico/8/1934 (H1N1, termed PR8 hereinafter) was obtained from the Smorodintsev Research Institute of Influenza (St. Petersburg, Russia). NIBRG-121xp, a 6:2 reassortant containing the internal proteins of influenza PR8 and the HA and neuraminidase (NA) proteins from influenza virus A/California/7/2009 (H1N1, termed CAL09 hereinafter) was obtained from the National Institute for Biological Standards and Control (NIBSC, Ridge, UK). Influenza viruses were propagated in nine-day-old embryonated hens' eggs at $37^{\circ} \mathrm{C}$ and titrated by TCID 50 using MDCK cells and the formula of Reed and Muench.

Streptococcus pneumoniae №3405, an invasive human serotype 4 isolate from a patient who died from pneumonia was obtained from the bacterial strain collection of the I. Mechnikov Research Institute for Vaccines and Sera (Moscow, Russia). For bacterial challenge, a freshly inoculated culture was grown to an $\mathrm{OD}_{600}$ of 0.6 in tryptic soy medium containing $5 \%(v / v)$ horse blood and was diluted in phosphate-buffered saline (PBS) to a concentration $12.5 \times 10^{6} \mathrm{CFU} / \mathrm{mL}$ prior to use.

\subsection{Production and Purification of Influenza HA-Gag VLPs}

Recombinant baculoviruses for the expression of HA-Gag and $\mathrm{Gag}_{\text {only-VLPs were generated as }}$ described in [22]. Briefly, the HA of A/Puerto Rico/8/1934 was expressed under control of the AcMNPV p10 promoter, whereas the HIV-1 Gag protein was under control of the AcMNPV pH promoter. VLPs were expressed by baculovirus infection of Tnms 42 cells in Fernbach flasks at a total expression volume of $1200 \mathrm{~mL}$ (HA-Gag VLPs) and $600 \mathrm{~mL}$ (Gagonly-VLPs) using a multiplicity of infection (MOI) of 2 and 1, respectively. Expression supernatants were harvested three days post infection and were clarified by two low-speed centrifugation steps $\left(800 \mathrm{~g}, 10 \mathrm{~min}, 4{ }^{\circ} \mathrm{C} ; 6000 \mathrm{~g}, 30 \mathrm{~min}, 4{ }^{\circ} \mathrm{C}\right)$ using a JLA.9100 rotor (Beckman Coulter, Brea, CA). Clarified supernatants were macrofiltrated in dead-end mode using $0.8 \mu \mathrm{M}$ syringe filters (Merck Millipore, Burlington, MA). Filtrated supernatants were about 11-fold concentrated and purified from soluble proteins by ultracentrifugation $\left(68,320 \mathrm{~g}, 2 \mathrm{~h}, 4{ }^{\circ} \mathrm{C}\right.$, Sw $32 \mathrm{Ti}$ rotor) using a $30 \%(w / v)$ sucrose cushion in $50 \mathrm{mM}$ HEPES pH 7.4. Concentrated and resuspended 
VLPs were dialyzed for $19 \mathrm{~h}$ against a total of 500 dialysis volumes of $50 \mathrm{mM}$ HEPES $\mathrm{pH} 7.4$ using Slide-A-Lyzer ${ }^{\mathrm{TM}} \mathrm{G} 2$ cassettes with a $10 \mathrm{kDa}$ cutoff (Thermo Fisher, Waltham, MA). Two different treatment methods were employed for live baculovirus inactivation. Dialyzed VLP suspensions were either treated with $5 \mathrm{mM}$ binary ethylenimine (BEI) (Sigma, St. Louis, MO) for $36 \mathrm{~h}$ or with $16 \mathrm{mM}$ $\beta$-propiolactone ( $\beta \mathrm{PL}$ ) (Acros Organics, Geel, BE) for $16 \mathrm{~h}$ at $37^{\circ} \mathrm{C}$ in a water bath. A $0.1 \mathrm{M}$ BEI solution was prepared, as previously described [22]. After inactivation, residual BEI or $\beta$ PL in the preparation was inactivated by $15 \mathrm{mM}$ or $160 \mathrm{mM}$ sodium thiosulfate $\left(\mathrm{Na}_{2} \mathrm{~S}_{2} \mathrm{O}_{3}\right.$, final concentration), respectively, and preparations were again dialyzed for $19 \mathrm{~h}$ against 500 dialysis volumes of $20 \mathrm{mM}$ HEPES pH 7.4. Samples were stored at $4{ }^{\circ} \mathrm{C}$ until further use.

\subsection{Characterization of HA-Gag VLPS}

Total protein content. Total protein content was determined using the Bradford assay in a 96-well microplate format. Briefly, $10 \mu \mathrm{L}$ of two-fold serial dilutions of the samples were incubated with $200 \mu \mathrm{L}$ Bradford reagent (Bio-Rad, Hercules, CA, USA) (1:5 diluted in $\left.\mathrm{ddH}_{2} \mathrm{O}\right)$ in duplicates for five minutes at room temperature (RT) and $\mathrm{OD}_{596}$ was measured on a Tecan Infinite M1000 microplate reader (Tecan, Männedorf, $\mathrm{CH})$. Data were fitted to a linear duplicate BSA standard curve (37.5-300 BSA $\mu \mathrm{g} / \mathrm{mL})$.

HA content. The HA content of the HA-Gag VLP preparations was determined using the Influenza A H1N1 (A/Puerto Rico/8/1934) Hemagglutinin/HA ELISA pair set (Sino Biological, Wayne, PA, USA) with some deviations from the manufacturer's protocol, as previously described [22]. Briefly, we employed a recombinant soluble, trimeric insect cell-expressed PR8 HA protein as calibration standard [26] and pre-treated samples with Zwittergent 3-14 for the solubilization of VLPs.

HA Activity. Hemagglutination activity of the HA-Gag VLP formulations was determined by hemagglutination assay. Briefly, serial two-fold dilutions of the vaccine preparations were prepared in 96-well V-shaped microplates in PBS in a total volume of $50 \mu \mathrm{L}$. Fifty $\mu \mathrm{L}$ of chicken red blood cells (cRBCs) isolated from fertilized hens' eggs, standardized at a cRBC concentration of $4 \times 10^{7} / \mathrm{mL}$, were added and plates were incubated at RT for $30 \mathrm{~min}$. The hemagglutination titer (HAU) was defined as the last sample dilution that resulted in complete hemagglutination of cRBCs.

Particle concentration. Particle concentration and size distribution were determined by nanoparticle tracking analysis (NTA) using a NanoSight NS300 (Malvern Instruments, Malvern, UK) equipped with a blue laser module $(488 \mathrm{~nm})$, a neutral density filter and a $500 \mathrm{~nm}$ fluorescence filter, as described elsewhere [29].

Residual BV infectivity. Five hundred microliter of each preparation (equals $50 \beta \mathrm{PL}_{\mathrm{low}} / \mathrm{BEI}_{\mathrm{low}}$

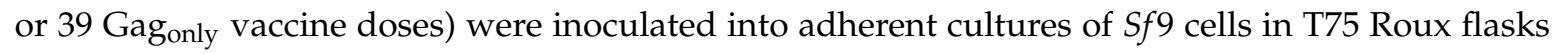
and were incubated for three days at $27^{\circ} \mathrm{C}$. Five hundred microliters of the harvested and clarified supernatants were further added to $S f 9$ cells and incubated for another three days. The absence of viral replication was verified by (1) the lack of YFP expression of inoculated cells, and (2) by the absence of baculovirus-mediated cytopathic effects.

\subsection{Immunization and Infection Protocol}

Mice were arbitrarily assigned to 14 study groups. No blinding was performed. Immunizations were performed via the intraperitoneal (IP)-route using a total volume of $100 \mu \mathrm{L}$ experimental vaccine or buffer. Influenza virus and pneumococcus infections were performed intranasally. Before intranasal procedures, mice were lightly anesthetized and were held in an upright position for viral (30 $\mu \mathrm{L} /$ nostril) or bacterial ( $50 \mu \mathrm{L} /$ nostril) infection.

To confirm loss of the BV adjuvant effect by viral inactivation and assess its implications for HA-specific humoral responses, mice ( $n=10$ per group) received a single IP-injection with either BEI-, $\beta$ PL-, or non-treated HA-Gag VLPs at a dose of 10 ng HA-Gag VLPs (termed BEI low, $\beta P L_{\text {low }}$, or live low $_{\text {, }}$ respectively), $\beta$ PL-treated Gag-VLPs normalized for the total protein content of HA-Gag VLPs (termed Gag $_{\text {only }}$ ), or were mock-vaccinated with buffer ( 20 mM HEPES pH 7.4). Five animals were sacrificed for the analysis of HA-specific antibodies in pre-challenge sera (see Section 2.7), while 
five animals were sacrificed for the assessment of innate immune activation at the vaccination site by analysis of type I/II interferon expression in peritoneal washes (see Section 2.9). To evaluate the efficacy of neutralizing or non-neutralizing influenza HA immunity in the context of secondary pneumococcal infections, animals were immunized and infected as per the study design, given in Figure 1. Four groups of animals were used for the assessment of neutralizing influenza HA-immunity in the context of secondary pneumococcus infections. There, mice were immunized with $\beta$ PL-or BEI-treated HA-Gag VLPs at a low antigen dose of $10 \mathrm{ng} \mathrm{HA}$ (termed $\beta \mathrm{PL}_{\text {low }}$, or $\mathrm{BEI}_{\text {low }}$, respectively, $n=26$ ), $\beta$ PL-treated Gag-only control VLPs normalized for the total protein content of HA-Gag VLPs (termed Gag only, $n=$ 21) or buffer [termed $(-)_{\mathrm{vacc}}, n=21$ ]. Three weeks later, animals were infected with $100 \mathrm{TCID}_{50}$ of homologous influenza virus PR8 followed by bacterial infection with $1.25 \times 10^{6} \mathrm{CFU}$ S. pneumoniae five days later. Six groups of animals were employed for the assessment of non-neutralizing influenza HA-immunity after influenza-pneumococcal superinfections. Among this set of mice, four groups of 25-26 animals received $\beta$ PL- or BEI-treated HA-Gag VLPs at a low (10 ng HA, termed $\beta P L_{l o w}$, or $\left.\mathrm{BEI}_{\text {low }}\right)$ or a high antigen dose $\left(100 \mathrm{ng} \mathrm{HA}\right.$, termed $\beta \mathrm{PL}_{\text {high }}$, or $\left.\mathrm{BEI}_{\text {high }}\right)$. Control groups received $\beta$ PL-treated Gag-only VLPs (termed Gagonly, $n=21$ ) normalized for the total protein content of to the low dose groups or were mock-immunized with buffer [termed $(-)_{\text {vacc }}, n=24$ ]. Twenty-one days post immunization mice were challenged with 1000 TCID $_{50}$ of a heterologous influenza H1N1 virus (CAL09) followed by bacterial superinfection with $1.25 \times 10^{6}$ CFU S. pneumoniae five days later.

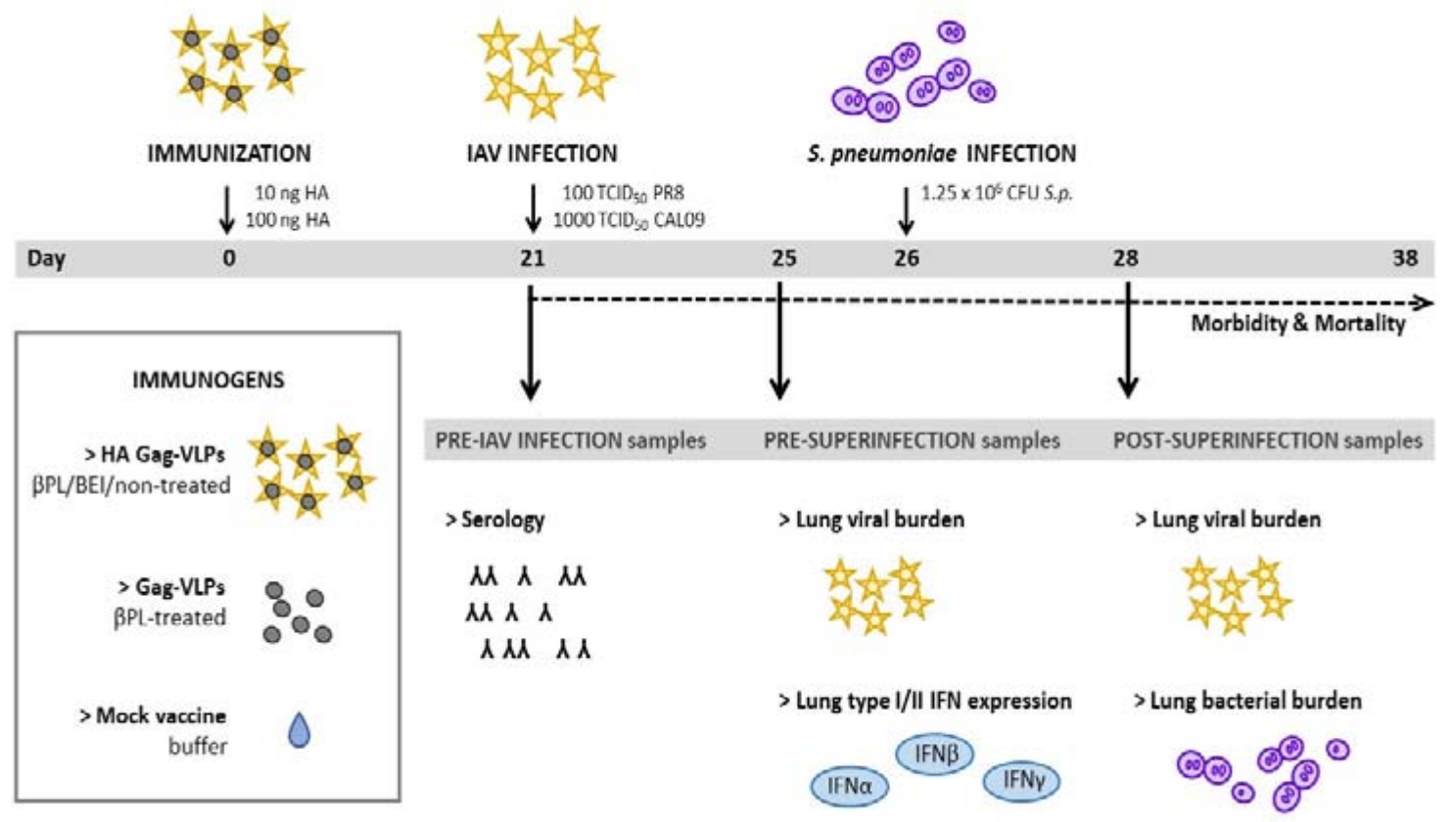

Figure 1. Study design. BALB/c mice were immunized by intraperitoneal injection (IP) with either a $\beta$ PL/BEI- or non-treated preparation of insect cell-expressed influenza hemagglutinin (HA)-Gag virus-like particles (VLPs), $\beta$ PL-treated Gag-VLPs or were mock-vaccinated with HEPES buffer. The HA was from PR8. Twenty-one days after immunization, mice were either challenged with 100 TCID $_{50}$ of homologous PR8 or 1000 TCID $_{50}$ of homosubtypic heterologous CAL09 (NIBRG-121xp) and received a secondary infection with $1.25 \times 10^{6} \mathrm{CFU}$ of a clinical serotype 4 strain of $\mathrm{S}$. pneumoniae five days later. Immunogenicity of the VLP preparations was assessed in pre-challenge sera three weeks post-immunization. The efficacy of anti-HA immunity in suppressing influenza-mediated innate type I/II interferon (IFN) expression and in limiting exacerbation of disease and mortality (pathogen burden, morbidity, and mortality) was evaluated.

To verify the lethal synergism of sequential influenza-pneumococcus infection, additional control groups were mock-immunized and were challenged with a single pathogen on the respective days of infection. Briefly, virus-only groups were infected with 100 TCID $_{50}$ PR8 (termed PR8-only, $n=18$ ) 
or 1000 TCID $_{50}$ CAL09 (termed CAL09-only, $n=19$ ) and were mock-infected with buffer five days later, while the bacterium-only group (termed S.p.-only, $n=14$ ) was mock-infected on day 21 and received $1.25 \times 10^{6} \mathrm{CFU}$ S. pneumoniae on day 26 . Mice were monitored for morbidity and mortality for 17 days after influenza virus infection. Weight was measured daily for five consecutive days post viral infection and was then measured every other day for the rest of the study period. Animals that lost $30 \%$ or more of their initial body weight were scored dead and humanely euthanized.

\subsection{Serology}

Twenty-one days post-immunization five mice per group were humanely euthanized for the determination of hemagglutination-inhibition titers (HI titers) in pre-challenge sera. Briefly, individual sera were treated with receptor-destroying enzymes (RDEs) (Denka Seiken, Tokyo, Japan) and were serially two-fold diluted with PBS in 96-well microplates before being mixed with influenza PR8 or CAL09, standardized at 8 HAU. Mixtures were incubated for $60 \mathrm{~min}$ at RT and then mixed with a solution of $0.5 \%(v / v)$ chicken RBCs in PBS. After incubation for $60 \mathrm{~min}$ at RT, hemagglutination was assessed. The HI titer was calculated from the reciprocal of the highest dilution that completely inhibited hemagglutination of red blood cells.

For the analysis of HA-specific total immunoglobulin G (IgG) titers and IgG isotype profiles, ninety-six-well flat-bottomed Nunc MaxiSorp immunoplates (Thermo Fisher, Waltham, MA, USA) were coated with recombinant insect-cell expressed soluble HA from PR8 containing a trimerization domain [30] at a concentration of $2 \mu \mathrm{g} / \mathrm{mL}$ in PBS at $4{ }^{\circ} \mathrm{C}$ overnight. The following day, plates were washed three times with $300 \mu \mathrm{L}$ PBS-Tween (PBS-T) and wells were blocked by the addition of $300 \mu \mathrm{L}$ PBS-T $+3 \%(w / v)$ dry-fat milk powder for one hour at room temperature. Serum samples were serially 1:2-diluted in PBS-T with a starting dilution of 1:100 and $100 \mu \mathrm{L}$ of each dilution was incubated with the coated antigen for two hours at room temperature. After washing three times with PBS-T, $50 \mu \mathrm{L}$ of either a horseradish peroxidase (HRP)-labeled goat anti-mouse IgG (\#A2304, Sigma, St. Louis, MI) or goat anti-mouse IgG1 (\#ab97240), IgG2a (\#ab97245) or IgG2b secondary antibody (\#ab97240, all Abcam, Cambridge, UK) was added at a dilution of 1:3000 in blocking buffer. After incubation for one hour at room temperature plates were again washed three times and were developed with 100 $\mu \mathrm{L}$ SIGMAFAST ${ }^{\mathrm{TM}}$ OPD substrate (Sigma, St. Louis, MI, USA) and stopped with $25 \mu \mathrm{L} 3 \mathrm{M} \mathrm{H}_{2} \mathrm{SO}_{4}$. The optical density was measured at $490 \mathrm{~nm}$ using a Tecan Infinite M1000 microplate reader (Tecan, Männedorf, Switzerland) and was normalized to blank.

\subsection{Analysis of Lung Pathogen Burden}

On day four afterviral infection four mice from all but the bacterial control group were euthanized by cervical dislocation for the titration of virus loads. Two days after bacterial superinfection (seven days after viral infection) viral and bacterial titers were determined in five mice per group from all study groups. Lungs were removed, thoroughly rinsed with sterile PBS to remove cellular debris and red blood cells and were homogenized and resuspended in one $\mathrm{mL}$ of cold PBS. For the titration of bacterial loads, 10-fold dilutions of lung homogenates were titrated on tryptic soy agar plates supplemented with $3 \%(v / v)$ sheep erythrocytes and S. pneumoniae colonies were counted. For virus titration, lung homogenates were centrifuged to remove cellular debris $(2000 \mathrm{~g}, 10 \mathrm{~min})$ and $0.1 \mathrm{~mL}$ of the clarified lung supernatants were injected into the allantoic cavity of nine-day-old embryonated hens' eggs to determine the $50 \%$ egg infective dose ( $\left.\operatorname{EID}_{50}\right)$.

\subsection{Analysis of type I/II Interferon Expression}

Type I/II interferon induction was evaluated (1) in peritoneal washes of mice $(n=5)$ receiving either $\beta$ PL/BEI- or non-inactivated HA-Gag VLPs at a dose of $10 \mathrm{ng}$ HA, $\beta$ PL-treated Gag-VLPs, or buffer six hours post-immunization and (2) in lung homogenates of immunized animals four days post-viral infection $(n=4-5)$. Briefly, for harvesting IP-washes, mice were sacrificed by cervical dislocation, and one $\mathrm{mL}$ of cold PBS was injected into the abdominal cavity using a syringe. Peritoneal 
washes were collected and clarified by centrifugation ( $3.500 \mathrm{rpm}, 5 \mathrm{~min})$. Lung homogenates were harvested as described in 2.8. IP-washes and lung homogenates were evaluated for the expression of IFN $\alpha / \beta$ and IFN $\gamma$ using a LEGENDplex mouse type I/II interferon bead-based multiplex assay (Biolegend, San Diego, CA) according to the manufacturer's instructions. Assay Buffer and beads were added to samples to reach a final volume of $75 \mu \mathrm{L}$ per well. Each sample and standard were run in duplicates. The samples were incubated in the dark on a plate shaker $(750 \mathrm{rpm})$ for two hours at room temperature. After washing with $200 \mu \mathrm{L}$ of Wash Buffer (centrifugation at $1100 \mathrm{rpm}$ for $5 \mathrm{~min}$ at $25^{\circ} \mathrm{C}$ ) samples were incubated with $25 \mu \mathrm{L}$ of the provided detection antibodies for one hour on a plate shaker. Subsequently, Streptavidin and R-phycoerythrin conjugates were added, and the samples were incubated for an additional $30 \mathrm{~min}$. Following centrifugation, the supernatants were discarded, samples were washed with $200 \mu \mathrm{L}$ of Wash Buffer, and analyzed using a CytoFlex Flow Cytometer (Beckman Coulter, Brea, CA, USA), and data were analyzed using the LEGENDplex Software, Version 8.0 (BioLegend, San Diego, CA, USA).

\subsection{Statistical Analyses}

All statistical analyses were performed with GraphPad Prism Version 8.1.0 (GraphPad Software, San Diego, CA, USA). Raw data were assessed for normality of distribution and homogeneity of variances using the D'Agostino-Pearson omnibus test and Brown-Forsythe test respectively before undergoing statistical procedures. Data that did not meet the requirements for parametric statistical tests were log-transformed before analysis. Statistical significance of differences in HI titers between groups was analyzed using One-Way analysis of variance (ANOVA) with the Tukey posthoc test correcting for multiple comparisons on the basis of log-transformed HI titers. Differences in viral titers between groups and between days were analyzed on the basis of log-transformed data using Two-Way ANOVA and a Tukey posthoc test or using Two-Way ANOVA and a Sidak correction factor, respectively. Log-transformed bacterial titers were analyzed by One-Way ANOVA and the Tukey posthoc test or a Kruskal-Wallis test with the Dunn correction factor (in case of non-normality of data). Values below the lower limit of detection (LLOD) were assigned a value of LLOD/2 for statistical analyses. The statistical significance of differences in cytokine concentrations were analyzed on log-transformed data by One-Way ANOVA with a Tukey correction factor or by Welch ANOVA followed by a Dunnett's T3 multiple comparison test (in case of variance inequality). The LLOD was defined strictly as the lowest analyte concentration of the standard curve, and extrapolated values below were considered as non-detectable. Bodyweight curves were analyzed by multiple t-tests with the assumption of similar standard deviations, and statistical significance was determined using the Holm-Sidak method. Mouse survival was analyzed by the Log-Rank (Mantel-Cox) test.

\section{Results}

\subsection{Study Design and Murine Superinfection Model}

We aimed to assess the distinct role of neutralizing and non-neutralizing immunity towards the influenza HA in preventing post-influenza pneumococcal disease and mortality in a murine BALB/c model. The HI assay was employed as a validated surrogate assay for the measurement of neutralizing anti-influenza immunity. We used a virus-like particle (VLP)-based immunogen due to several reasons: (1) VLPs enabled us to investigate immunity conferred by a single influenza antigen and (2) VLPs allow for the presentation of the HA in its native conformation in particulate and highly immunogenic form [31,32]. We inactivated BV impurities in our preparations with alkylating agents ( $\beta$ PL or BEI) with the aim of abolishing BV-mediated adjuvant effects. Mice were immunized by IP-injection of HA-Gag VLP preparations at different dose levels (termed $\beta \mathrm{PL}_{\text {low/high, }}, \mathrm{BEI}_{\text {low/high }}$, live $\mathrm{low}_{\text {low }}$ ), control VLPs (termed Gag $_{\text {only }}$ ) or were mock-vaccinated with buffer [termed $(-)_{\text {vacc }}$ ]. Low antigen doses corresponded to $10 \mathrm{ng}$ of HA, while high doses were equal to $100 \mathrm{ng}$ of HA. The intraperitoneal route of immunization was chosen due to its technical convenience and because it ensures fast drainage 
of antigen-presenting cells (APCs) to local lymph nodes and thereby results in robust B- and T-cell responses [33]. Twenty-one days post-immunization mice were intranasally infected with either homologous HA-matched influenza PR8 or a heterologous, non-matched influenza virus of the same subtype (CAL09). Previous studies in this field revealed that $S$. pneumoniae is highly lethal when administered within five to seven days post influenza infection $[12,34,35]$. Therefore, the sequential viral-bacterial-infection model was set up accordingly, and animals were challenged with bacteria five days post-influenza infection and samples were collected, as indicated in Figure 1.

To characterize the two employed superinfection models we performed mono- or dual-infections with viruses and bacteria as outlined in Figure 1. Mice mono-infected with a viral dose of 100 TCID $_{50}$ of influenza PR8 or 1000 TCID $_{50}$ of CAL09 demonstrated mean viral pulmonary day four titers of 7.5 and $5.8 \log _{10} \mathrm{EID}_{50} / \mathrm{mL}$, respectively, which dropped significantly on day 7 (Figure S1A). In stark contrast, bacterial superinfections lead to a rebound in viral titers on day 7 (both $p_{\text {adj }}<0.0001$ ). At the same time, influenza-infected mice displayed significantly higher pulmonary bacterial loads than mice without a history of influenza (Figure S1B). While the pneumococcal mono-infection was non-lethal in mice, antecedent infection with influenza PR8 or CAL09 dramatically enhanced severity of the disease leading to $100 \%$ mortality within two or eight days post bacterial infection, respectively (Figure S1C,D).

\subsection{Effect of Baculovirus Inactivation on Influenza VLP Immunogenicity}

Purified insect cell-derived enveloped VLPs may contain bioprocess-derived, co-purified baculovirus impurities that are commonly inactivated with alkylating agents, such as $\beta P L$ or BEI, for in vivo studies [36,37]. $\beta \mathrm{PL}$ is routinely employed for the manufacturing of inactivated influenza vaccines but was associated with amino acid modifications that affect HA function and antigenicity [36,38-40]. BEI is suggested to preserve protein conformation and antigenicity better [40], but has been less frequently used for the preparation of experimental influenza vaccines. We, therefore, aimed to compare how these two inactivation strategies influence HA function and HA-specific humoral immunity and protective efficacy.

Neither of the employed inactivation protocols affected the structural integrity of VLPs (Figure 2A) or the hemagglutination capacity of the HA (Figure 2B). The latter of which suggests that antigenic sites close to the receptor-binding domains have been functionally preserved. Five hundred microliter of the undiluted inactivated VLP preparations (equal to 50 low antigen doses) were inoculated in cell culture flasks containing $S f 9$ cells and resulted in no detectable expression of the infection reporter YFP (data not shown). Baculoviruses are potent inducers of innate immunity as they trigger type I/II IFN expression and recruitment of immune cells to the site of immunization [41-43]. We aimed to confirm the elimination of the BV adjuvant effect after chemical treatment and assessed interferon responses at the injection site six hours post-immunization (Figure 2C). In accordance with previous studies, we observed elevated IFN $\alpha$ and IFN $\gamma$ expression in peritoneal washes of mice immunized with a non-treated HA-Gag VLP formulation containing $1.7 \times 10^{5}$ pfu infectious BVs [41,44]. BV inactivation with $\beta$ PL eliminated IFN $\alpha(p=0.0006)$ and IFN $\gamma$ induction $(p<0.0001)$ at the site of vaccination. Similarly, IFN $\alpha$ and IFN $\gamma$ expression in mice immunized with BEI-treated HA-Gag VLPs or $\beta$ PL-treated Gag only control VLPs was successfully reduced [IFN $\alpha: p_{a d j}=0.0004\left(\mathrm{Gag}_{\text {only }}\right)$, IFN $\gamma$ : $\left.p_{a d j}=0.0297\left(\mathrm{BEI}_{\mathrm{low}}\right), p_{a d j}=0.0219\left(\mathrm{Gag}_{\text {only }}\right)\right]$, but was not completely abolished. None of the groups demonstrated IFN $\beta$ expression in peritoneal washes six hours post-immunization. 

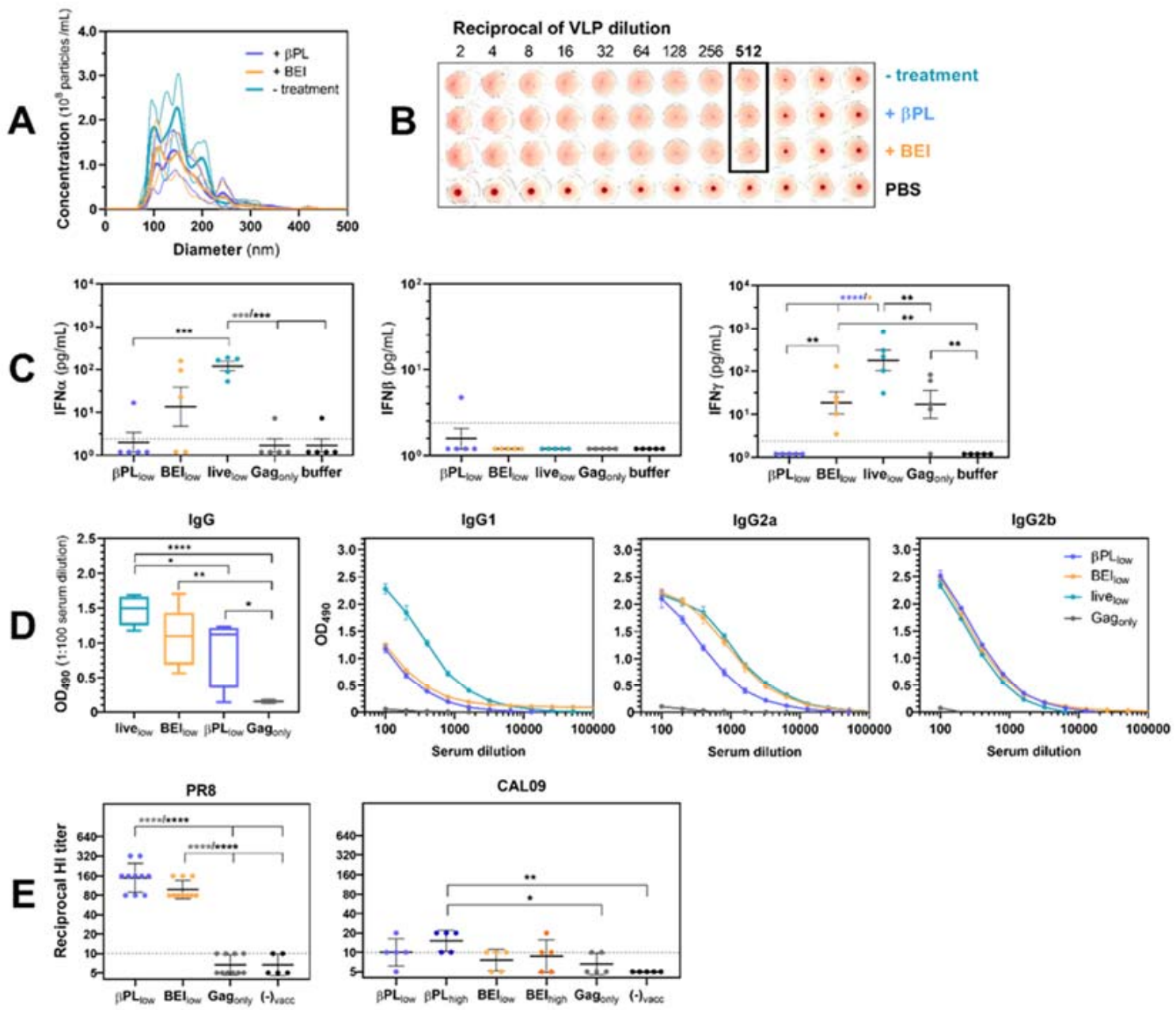

Figure 2. Effect of baculovirus inactivation on influenza VLP vaccine immunogenicity. (A) Preservation of the particulate integrity and (B) HA activity of the VLP formulations after treatment with $16 \mathrm{mM}$ $\beta P L$ or $5 \mathrm{mM}$ BEI for $16 \mathrm{~h}$ and $36 \mathrm{~h}$ at $37^{\circ} \mathrm{C}$ respectively was verified by dynamic light scattering analysis and hemagglutination assay, respectively. Broad and narrow lines in panel (A) give the mean and SD of the measured particle concentrations, respectively. (C) Abolishment of vaccine vector-induced local innate immune activation reflected by IFN $\alpha, \operatorname{IFN} \beta$ and IFN $\gamma$ expression was evaluated six hours post-IP-immunization with the respective VLP preparations or buffer in peritoneal washes of mice $(n=5$ per group). Data represent log-transformed results for individual animals and group means \pm SEM. (D) The effect of baculovirus (BV)inactivation on the magnitude and quality of the PR8 HA-specific humoral response was assessed in mouse serum samples taken three weeks post-immunization. Total IgG titers were determined from individual sera ( $n=5$ per group), IgG1, IgG2a, and IgG2b isotype levels were determined in pooled sera in duplicates. (E) HI antibodies against the vaccine-matched influenza PR8 or the non-matched CAL09 challenge strain were assessed in pre-challenge sera $(n=4-10)$. Color code vaccine groups: $\beta \mathrm{PL}_{\text {low }}$ (light blue), $\beta \mathrm{PL}_{\text {high }}$ (dark blue), $\mathrm{BEI}_{\text {low }}$ (light orange), $\mathrm{BEI}_{\text {high }}$ (dark orange), live $_{\text {low }}$ (turquoise), Gagonly (grey), Non-vaccinated (black). Symbols represent HI titers of individual mice, lines and error bars indicate the group geometric mean titer and SD. Dashed lines indicate the lower limit of detection (LLOD) at a HI titer of 1:10. Statistical significance of differences in mean IFN titers, IgG titers, and HI titers (log-transformed data) were analyzed by One-Way ANOVA and a Tukey correction factor with ${ }^{*} p_{\text {adj }}<0.05,{ }^{* *} p_{\text {adj }}<0.01,{ }^{* * *} p_{\text {adj }}<0.001$, and ${ }^{* * *} p_{\text {adj }}<0.0001$.

Due to their adjuvant properties, infectious baculoviruses were shown to enhance humoral and cellular responses against co-administered antigens in mice [36,43,44]. We sought to assess the implication of BV inactivation on the magnitude and quality of humoral responses in pre-challenge sera collected 21 days post-immunization (Figure 2D). Serum IgG titers were highest after immunization 
with formulations capable of IFN-induction. $\beta P L-m e d i a t e d$ BV inactivation was accompanied by the greatest reduction in total serum IgG concentration $\left(p_{a d j}=0.0492\right)$. Immunization with a formulation containing live baculovirus elicited a balanced IgG1:IgG2a:IgG2b antibody response. The immunoglobulin subclass profile elicited by both inactivated HA-Gag VLP preparations was characterized by a reduction in IgG1 antibodies, indicating a shift towards a Th1 immune response. To test the functionality of the antibodies, pre-challenge serum samples were tested for the induction of $\mathrm{HI}$ antibodies (neutralizing antibodies) for the respective challenge strains (Figure 2E). Mice immunized with $\beta$ PL-treated and BEI-treated HA-Gag VLPs at a dose of $10 \mathrm{ng}$ HA displayed comparable HI titers against PR8 ( $\beta$ PL $L_{\text {low }}$ : GMT 149.3; $\mathrm{BEI}_{\text {low }}: 98.5, p=0.1213$ ). Only mice immunized with $\beta P L_{h i g h}$ consistently demonstrated detectably, but low, HI titers against CAL09 (GMT, 15.6, $p=0.007$ ).

\subsection{Effective Anti-HA Immunity Suppresses Influenza-Mediated IFN Type I/II Responses in the Lungs of Infected Mice}

Interferon type $\mathrm{I} / \mathrm{II}$ expression in response to an influenza virus infection is a host factor suggested to increase the susceptibility of an individual to secondary bacterial infection [5-8,14,45,46]. IFN signaling was associated with the negative regulation or depletion of innate immune cells critical for early bacterial control $[5,7,11,12,34]$. In an effort to evaluate whether neutralizing and non-neutralizing anti-HA immunity can prevent this host sensitization, we assessed pulmonary concentrations of IFN $\alpha$, IFN $\beta$ and IFN $\gamma$ one day before bacterial challenge (Figure 3A-C).

Non-vaccinated, PR8-infected animals displayed significantly higher pulmonary IFN $\beta$ (1.6-log increase, $\left.p_{a d j}=0.0066\right)$ and IFN $\gamma$ concentrations (2.8-log increase, $\left.p_{a d j}=0.0305\right)$ than naïve mice (Figure 3B,C, left panels). Immunization with HA-matched VLP preparations, irrespective of the BV inactivation method, could dampen influenza-induced cytokine expression to concentrations observed in naïve mice (Figure 3C, left panel). IFN $\beta$ and IFN $\gamma$ expression levels in the lungs of

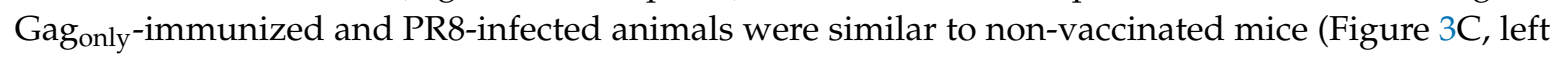
panel). To our surprise, non-vaccinated, CAL09-infected mice demonstrated no increase in lung type I/II IFN expression in comparison to naïve, non-infected mice (Figure 3, right panels). We also observed no differences in type I/II IFN expression between immunized and non-immunized, infected animals. Interestingly, the group of mice immunized with $\mathrm{Gag}_{\text {only }}$-VLPs exhibited the most homogenous IFN response pattern among all analyzed groups and displayed significantly elevated IFN $\gamma$ expression compared to naïve mice (2-log higher, $p=0.0445$ ) (Figure 3C, right panel). In general, there was a trend for higher type I/II IFN expression in the lungs of animals immunized with BEI-treated HA-Gag

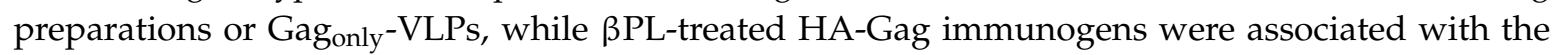
lowest induction of interferons after CAL09 infection. 

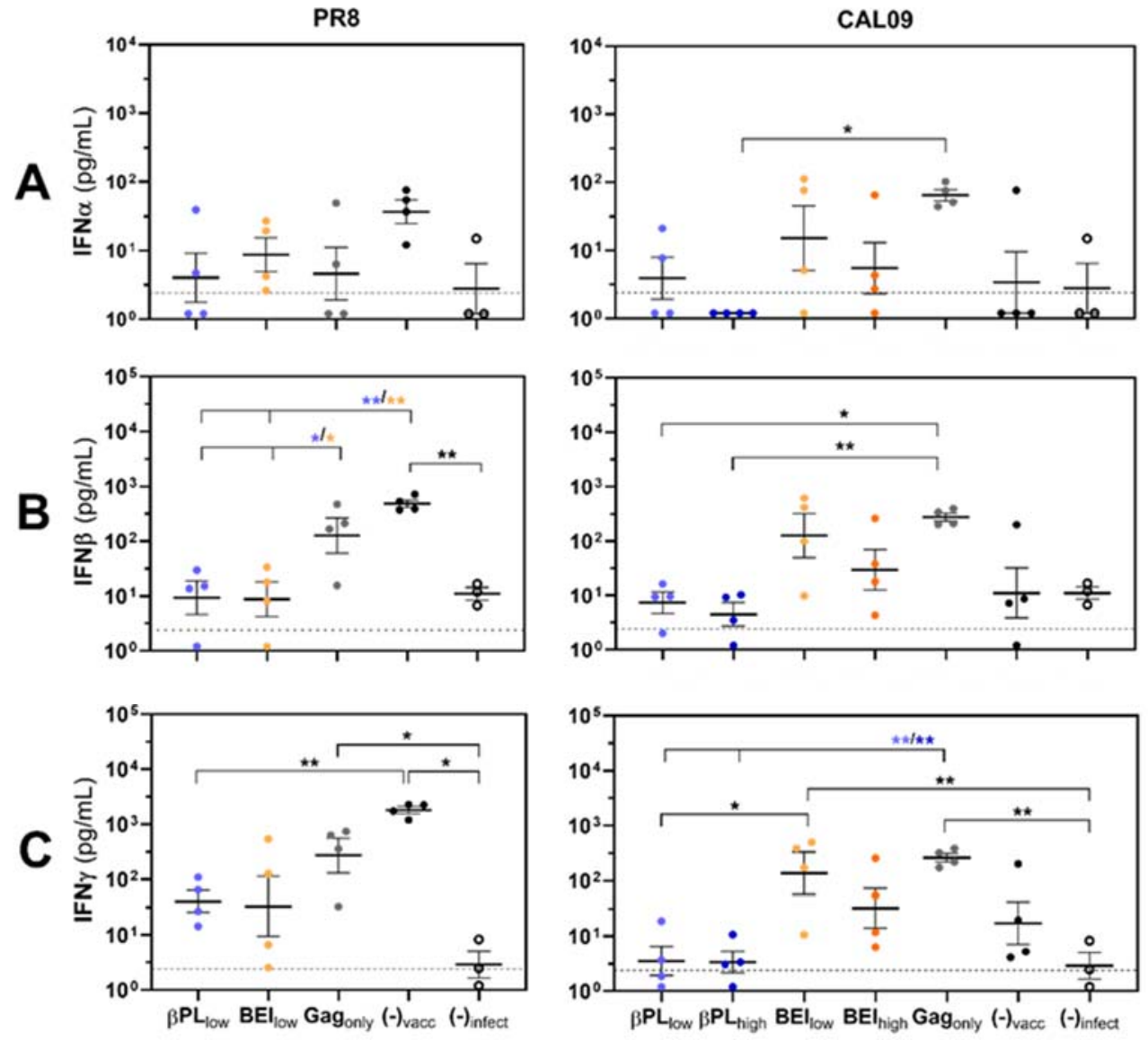

Figure 3. Effective anti-HA immunity suppresses influenza-mediated IFN type I/II responses in the lungs of infected mice. Lung homogenates from immunized or mock-vaccinated mice ( $n=4$ per group) infected with vaccine-matched PR8 (left panel) or non-matched CAL09 (right panel) were analyzed for the expression of (A) IFN $\alpha$, (B) IFN $\beta$, and (C) IFN $\gamma$ four days post-viral infection. Basal type I/II IFN expression levels were analyzed in naïve, non-infected mice $(n=3)$. Symbols represent the mean IFN concentration of a duplicate measurement from a single mouse and lines and error bars indicate group means +/- SEM. Color code vaccine groups: $\beta P L_{\text {low }}$ (light blue), $\beta P L_{\text {high }}$ (dark blue), $\mathrm{BEI}_{\text {low }}$

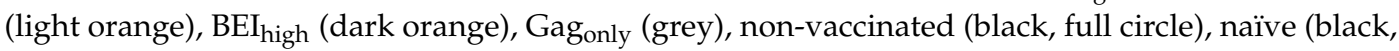
open circle). Statistical significance of differences in mean IFN-concentrations between groups was analyzed by One-Way ANOVA and a Tukey posthoc test or by Welch ANOVA followed by a Dunnett's T3 posthoc test for multiple comparisons (C, left panel) on basis of log-transformed data. The dashed line indicates the defined LLOD and represents the lowest analyte concentration of the calibration curve $(2.4 \mathrm{pg} / \mathrm{mL})$. Asterisks indicate the significance level giving adjusted $p$-values for multiple comparisons with * $p_{a d j}<0.05$ and ${ }^{* *} p_{a d j}<0.01$.

\subsection{Neutralizing and Non-Neutralizing Anti-HA Immunity Restrain Viral Replication and Viral Rebound} After Secondary Pneumococcus Infection

We next studied the effect of vaccine-matched (neutralizing) and vaccine-mismatched (non-neutralizing) anti-HA immunity on viral replication in the lungs one day before and two days after bacterial superinfection. Non-vaccinated mice displayed high viral pulmonary titers on day four (mean titer +/- SEM: 7.5 +/- $0.288 \log _{10}$ EID $_{50} / \mathrm{mL}$ ) and titers increased about 400-fold $\left(p_{a d j}<0.0001\right)$ after bacterial secondary infection (Figure $\left.4 \mathrm{~A}\right)$. 


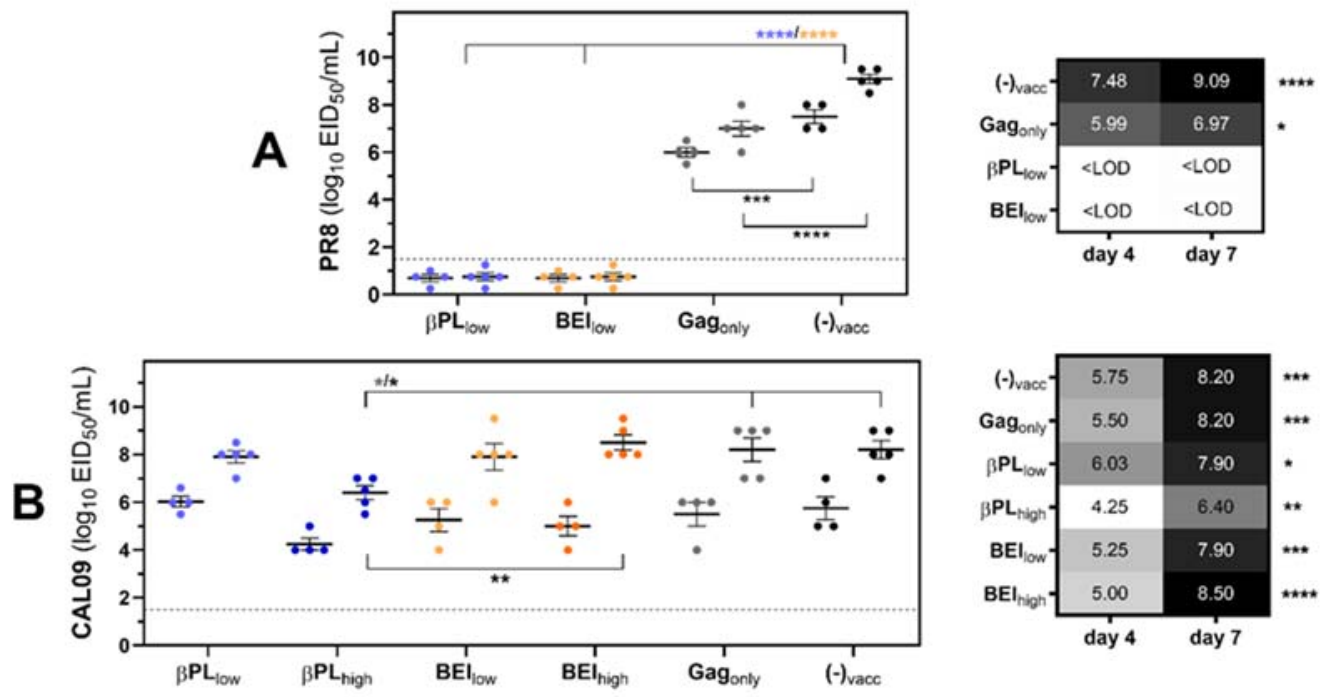

Figure 4. Neutralizing and non-neutralizing anti-influenza HA immunity restrains viral replication and viral rebound after secondary pneumococcus infection. Mice received one intraperitoneal dose of the respective preparations or buffer, and on day 21 were intranasally infected with influenza followed by S. pneumoniae challenge five days later. Viral pulmonary loads were analyzed in mice ( $n=4-5$ per group) infected with (A) 100 TCID $_{50}$ of homologous influenza PR8 or (B) 1000 TCID $_{50}$ of homosubtypic heterologous CAL09. Figures give viral day four titers (one day before bacterial challenge) juxtaposed with day seven titers (two days post bacterial challenge) for each vaccine group. Color code vaccine groups: $\beta \mathrm{PL}_{\text {low }}$ (light blue), $\beta \mathrm{PL}_{\text {high }}$ (dark blue), $\mathrm{BEI}_{\text {low }}$ (light orange), $\mathrm{BEI}_{\text {high }}$ (dark orange), Gag only (grey), non-vaccinated (black). Symbols represent the titer of an individual mouse and lines and error bars indicate group mean titers +/- SEM. Heatmaps display group mean viral pulmonary titers on day four and day seven. The dashed line at $1.5 \log _{10} \mathrm{EID}_{50} / \mathrm{mL}$ indicates the LLOD. Viral titers were log-transformed and differences between groups and between days were analyzed by Two-Way ANOVA followed by a Tukey posthoc test or a Sidak posthoc test, respectively, with * $p_{a d j}<0.05,{ }^{* *} p_{a d j}<0.01,{ }^{* * *} p_{a d j}<0.001$, and ${ }^{* * *} p_{a d j}<0.0001$.

Immunization with $\beta \mathrm{PL}_{\text {low }}$ or $\mathrm{BEI}_{\text {low }}$ could fully restrict $\mathrm{PR} 8$ replication on day four post-infection $\left(p_{a d j}<0.0001\right)$. Interestingly, despite the absence of an influenza antigen, Gagonly-immunized mice displayed reduced pulmonary PR8 titers on day four $\left(p_{a d j}=0.0027\right)$ and seven $\left(p_{\text {adj }}<0.0001\right)$ and a lower rebound in viral titers after bacterial superinfection (Figure 4A). In contrast, PR8 HA-specific immunity did not restrain CAL09 virus replication on day four (range: 4.3-6.0 $\log _{10} \mathrm{EID}_{50} / \mathrm{mL}$ ) or lower the rebound in viral titers after S. pneumoniae superinfection (Figure 4B). Yet, we observed a reduction in CAL09 day seven titers in mice immunized with $\beta P L_{h i g h}$. There, the viral load after the secondary infection was 1.8- $\log \left(p_{a d j}=0.0163\right)$ or 2.1-log $\left(p_{a d j}=0.0033\right)$ lower than in non-vaccinated or $\mathrm{BEI}_{\text {high }}$-immunized animals, respectively.

\subsection{Neutralizing Anti-Influenza HA Immunity Renders Mice Capable of Controlling a Secondary Pneumococcal Infection}

We confirmed that influenza virus infection with both viral strains suppressed antibacterial control (Figure S1B) and we, therefore, investigated whether homologous, neutralizing and heterologous, non-neutralizing anti-HA immunity can revert this effect. Bacterial growth was evaluated in the lungs of immunized and influenza-infected animals two days after secondary bacterial infection (Figure 5). 

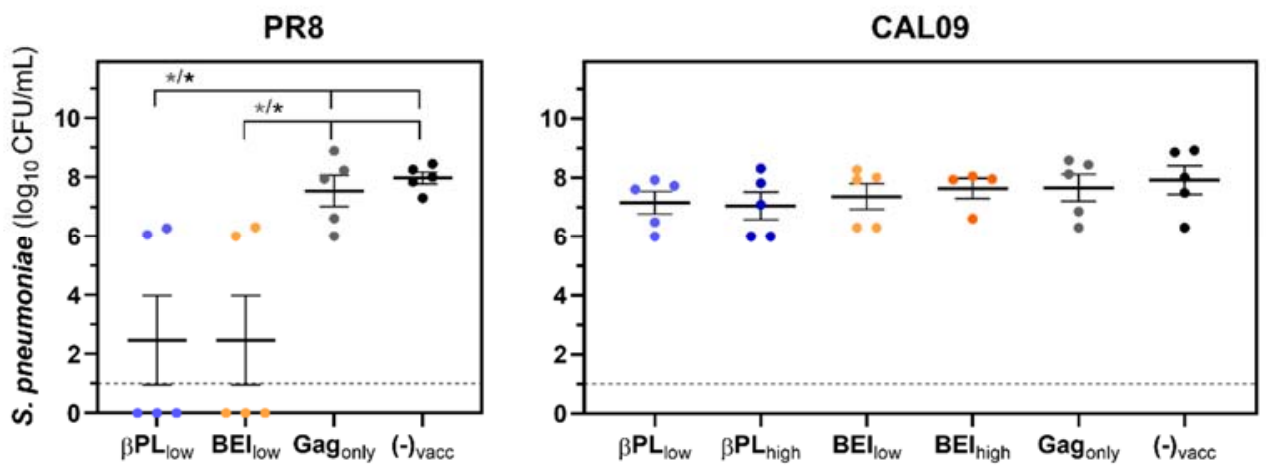

Figure 5. Neutralizing anti-influenza HA immunity renders mice capable of controlling a secondary pneumococcal infection. Immunized or mock-immunized and PR8-infected (left panel) or CAL09-infected mice (right panel) were challenged with $1.25 \times 10^{6} \mathrm{CFU}$ of a clinical serotype 4 strain of S. pneumoniae five days post influenza and the bacterial burden was assessed in the lungs of mice two days after bacterial infection ( $n=3-5$ per group). Color code vaccine groups: $\beta \mathrm{PL}_{\mathrm{low}}$ (light blue), $\beta \mathrm{PL}_{\text {high }}$ (dark blue), $\mathrm{BEI}_{\text {low }}$ (light orange), $\mathrm{BEI}_{\text {high }}$ (dark orange), $\mathrm{Gag}_{\text {only }}$ (grey), non-vaccinated (black). Symbols represent the titer of an individual mouse and lines and error bars indicate group means +/- SEM. The dashed line indicates the LLOD of the assay. Statistical significance of mean titers between groups was analyzed by One-Way ANOVA and the Tukey posthoc test or a Kruskal-Wallis test with a Dunn's correction factor on basis of log-transformed data with * $p_{\text {adj }}<0.05$.

Neutralizing anti-HA immunity was associated with a significant reduction $(-5.5 \log \mathrm{CFU} / \mathrm{mL}$, $\left.p_{a d j}=0.0132\right)$ of the mean bacterial density in the lungs of immunized mice in contrast to non-vaccinated animals (Figure 5, left panel). In three out of five mice, pneumococcus was completely cleared from the lungs. Two mice exhibited bacterial loads similar to what we observed in animals mono-infected with

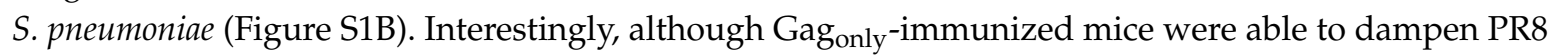
virus replication in the lungs (Figure $4 \mathrm{~A}$ ), they were not able to lower the pneumococcal burden two days after bacterial challenge $\left(p_{a d j}=0.992\right)$. We observed no reduction in bacterial pulmonary titers in mice immunized with mismatched HA-Gag VLP preparations (Figure 5, right panel).

\subsection{Influenza-Specific and Non-Specific Immunity Provide a Survival Advantage After Secondary Pneumococcal Infection}

Influenza vaccination with IIVs and LAIVs has proven beneficial for preventing lower respiratory tract complications and death from secondary pneumococcal infections in murine models [20,21]. Yet, no such study assessed the impact of neutralizing or non-neutralizing anti-HA immunity alone in a lethal in vivo influenza-pneumococcus infection model.

Immunization with $\beta \mathrm{PL}_{\text {low }}$ and $\mathrm{BEI}_{\text {low }}$ protected mice from morbidity associated with homologous influenza virus infection (Figure 6A, left panel). In these groups weight loss was significantly lower than in non-vaccinated animals within the first five days after viral infection $\left[(-)_{\text {vacc }}:-19.9 \%, \beta\right.$ PL: $-7.2 \%$, BEI: $-3 \%$; both $\left.\left.p_{a d j}<0.0001\right)\right]$. After secondary infection, all non-vaccinated mice $(11 / 11)$ reached the clinical endpoint for humane euthanasia within two days after bacterial inoculation (median survival time: seven days). In contrast, matching influenza HA-immunity elicited by $\beta \mathrm{PL}_{\text {low }}$, and $\mathrm{BEI}_{\text {low }}$ prevented mortality in eight $(73 \%)$ and seven $(64 \%)$ out of 11 animals, respectively (both $p<0.0001$ ) (Figure 6B, left panel). Interestingly, also immunization with control-VLPs (Gagonly) conferred partial protection from mortality (three out of 11 mice, $27.7 \%$; $p=0.0308$ ), but did not prolong median survival time. Sequential infection with CAL09 + S. pneumoniae was 100\% lethal for non-vaccinated mice with a median survival time of seven days, but with slightly slower mortality kinetics compared to infection

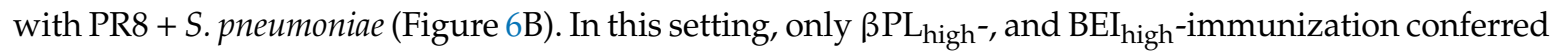
significant protection from mortality (5/11 mice, $p=0.0093$ and 4/11 mice, $p=0.014$, respectively) and prolonged median survival to 13 and 12 days, respectively. We observed no significant protection 
from mortality associated with sequential CAL09-pneumococcus infection in animals immunized with Gag $_{\text {only }}$ control VLPs $(p=0.1778)$.

PR8

A
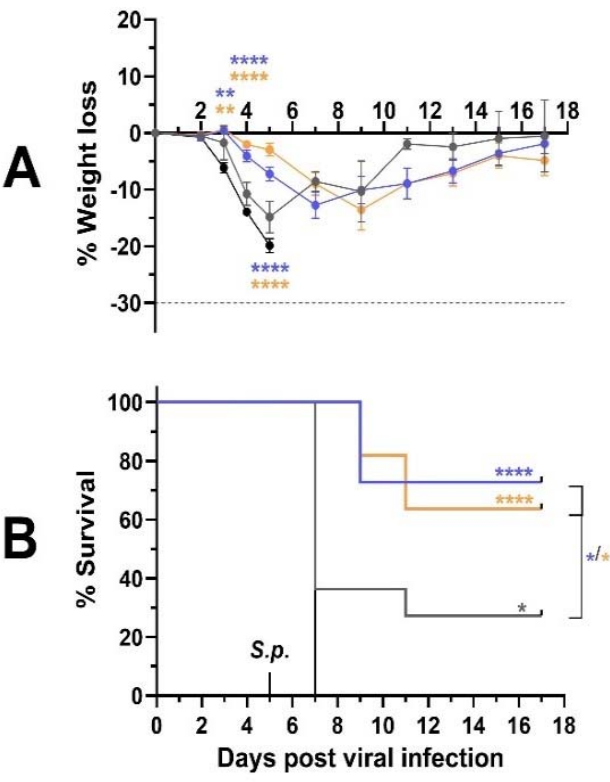

CAL09

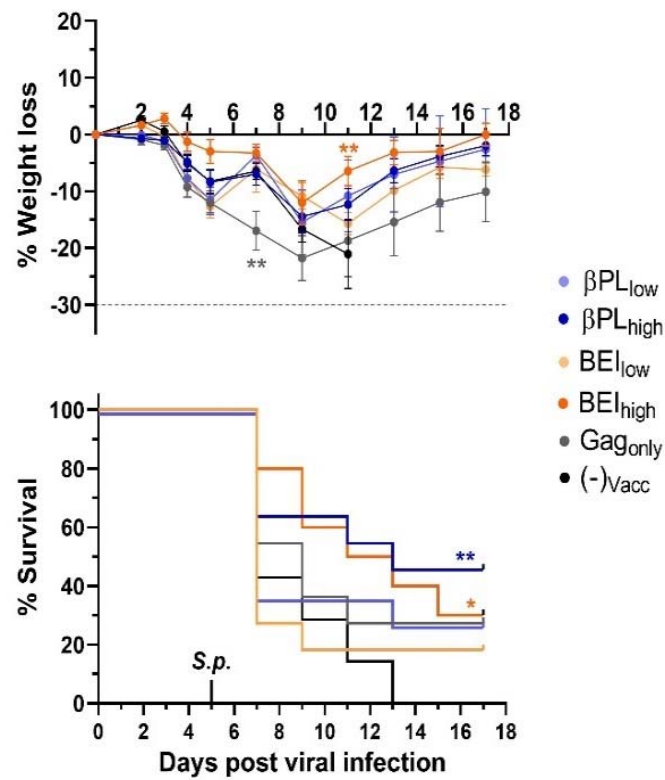

Figure 6. Influenza-specific and non-specific immunity provides a survival advantage after secondary pneumococcal infection. Mice received one intraperitoneal dose of HA-Gag VLPs at low HA antigen dose (10 ng), control VLPs or buffer or (C) VLPs at a high HA antigen dose (100 ng) or buffer. Three weeks later, mice were infected with homologous influenza PR8 or homosubtypic heterologous CAL09 followed by bacterial challenge with S. pneumoniae five days post influenza infection. Weight loss (A) and survival (B) was monitored over a period of 17 days post-viral infection. Animals that lost $30 \%$ of their initial body weight (dashed line) were scored dead and humanely euthanized. Data represent the mean weight of each group +/- SEM. Weight loss curves were analyzed with multiple t-tests using the Holm-Sidak correction factor for multiple comparisons, and survival curves were analyzed with the Log-Rank test, with ${ }^{*} p_{\text {adj }}<0.05,{ }^{* *} p_{\text {adj }}<0.01$ and ${ }^{* * * *} p_{\text {adj }}<0.0001$.

\section{Discussion}

The link between influenza and secondary bacterial infection has been recognized for many years. There is a large body of research showing that influenza-mediated physical and physiological changes of the host leave an individual more susceptible to bacterial superinfection $[5,6,8,12,46,47]$. Yet, influenza vaccine-induced immunity is almost exclusively evaluated using protection from disease or mortality after an influenza infection as the study endpoint. The potential of influenza vaccination to abrogate the lethal viral-bacterial synergism remains a little-investigated field. In the present study, we demonstrated that neutralizing influenza HA head-directed immunity conferred by different HA-Gag VLP formulations allowed BALB/c mice to control a secondary pneumococcal infection better and reduced mortality from $100 \%$ to $27 \%$ or $36 \%$, respectively (both $p<0.0001$ ). This is impressive, considering the low non-adjuvanted antigen dose of $10 \mathrm{ng}$ HA and the single immunization regimen we employed. It is, however, also indicative of the multifaceted interplay between viral, host, and bacterial factors that have to be considered, since $30-40 \%$ of mice could not be protected from mortality despite (1) high HI antibody titers (2) effective control of viral replication, and (3) successful reduction of the bacterial lung burden.

Interferon induction is an innate immune response to viral infection and type I/II IFNs are collectively acknowledged for their antiviral and immune-stimulatory activities [48,49]. Nevertheless, there is increasing evidence of the detrimental effects of interferon signaling in the context of SBIs 
post-influenza $[5,7,34]$. We, therefore, assessed interferon induction in the lungs of immunized and influenza-infected mice before secondary bacterial infection with the aim to relate the degree of innate immune induction to the capability of mice to control bacterial outgrowth. Experimental studies indicate that bacterial infections coinciding with a narrow time window of influenza-induced IFN expression result in unrestricted bacterial growth with severe consequences [7,34,35]. Indeed, mice deficient in type I IFN signaling (IFNR ${ }^{-}$- knock-out mice) could adequately produce chemoattractants that guide neutrophil recruitment to the site of infection. This eventually resulted in improved secondary bacterial clearance and survival in contrast to wild type mice $[5,34,46]$. Similarly, pulmonary IFN $\gamma$ abundance induced by influenza virus infection can be mimicked by direct IFN $\gamma$ inoculation and was shown to suppress pulmonary antibacterial defense mechanisms. This phenotype, however, could be prevented by antibody-mediated IFN $\gamma$ neutralization after influenza infection [7]. In our study, anti-HA immunity conferred by two differentially treated HA-Gag VLP preparations restrained homologous viral replication by day four post-infection and thereby dampened innate type I/II IFN expression in the lungs. In this setting, $60 \%$ of mice were capable of fully controlling bacterial outgrowth two days after bacterial infection. We assume that neutralizing anti-HA immunity could counteract virus-mediated IFN responses of the host and thereby rescue its phagocytic and bactericidal capacity to rapidly clear the pneumococcal challenge dose.

Considering the incomplete protection provided by neutralizing anti-HA immunity we were surprised that non-influenza-specific immunity conferred by immunization with Gagonly VLPs was associated with a significant reduction in viral titers and protection from mortality $(27 \%, p=0.0308)$ in the absence of suppressing bacterial replication. It is of note that upon inoculation of a volume equal to

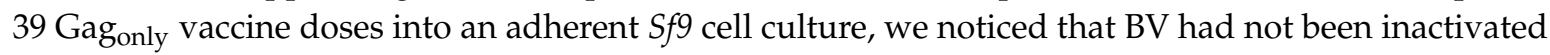
to the completeness, as we observed a few cells expressing the YFP infection reporter (data not shown). This was in contrast to what we observed for HA-Gag formulations. Gag only-immunization, therefore, resulted in the activation of innate immunity, such as IFN $\gamma$ expression at the site of immunization. Interestingly, these mice also exhibited significantly elevated pulmonary IFN $\gamma$ concentrations after infection with PR8 or CAL09. Infectious baculoviruses possess strong adjuvant activities due to the presence of abundant unmethylated CpG motifs throughout their viral genome [50]. Unmethylated CpG motifs are sensed by mammalian Toll-like receptor 9 (TLR9), a protein component of the innate immune system expressed in many immune cells. Infectious baculovirus was demonstrated to activate murine NK cells either directly via TLR9 [51] or indirectly via cytokine signaling of transduced murine DC cells [42]. NK cells that had been previously activated by cytokines were shown to have a cell-intrinsic enhanced capacity to respond to secondary stimuli and produce more IFN $\gamma$ upon restimulation [52]. We speculate that innate immune training by live baculovirus present in

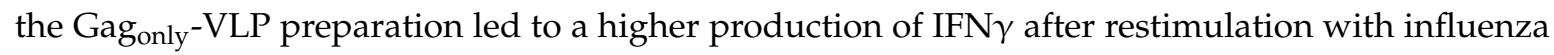
virus. Thereby, the virus may have encountered an immunologically primed environment with higher numbers of activated macrophages, neutrophils, and natural killer cells. Some of these cells are professional antigen-presenting cells, and likely may have had superior antigen-presenting properties upon restimulation with influenza virus. The phenomenon of trained immunity was also observed by Norton and colleagues in BALB/c mice that received CpG oligodeoxynucleotides one day before being challenged with a lethal dose of influenza PR8 [53]. CpG administration induced a local inflammatory response that resulted in a significant reduction in morbidity and mortality upon influenza infection. In our study, the time span between vaccine-induced innate immune activation and re-activation by virus encounter is much longer (3 weeks). In this respected, it would have been of interest to assess the duration of the primed functional state elicited by residual baculovirus in the preparation. These are important results, as innate immune training may open a door for novel vaccine formulations that unlike conventional vaccines, which focus on the elicitation of a specific response to the nominal pathogen, non-specifically stimulate immunity against a wider array of pathogens.

Treatment of the VLP preparations with alkylating agents, such as $\beta$ PL or BEI, results in the alkylation of nucleotides other than thymidine or uracil and induces DNA nicks or crosslinks DNA 
strands [54]. $\beta$-propiolactone is of widespread industrial use. It is commonly employed for the preparation of IIVs and for baculovirus inactivation in preparations intended for preclinical use [36,55]. In contrast to previous beliefs, studies demonstrated $\beta P L$ to react with several amino acids (most notably with cysteine, methionine and histidine residues) [55] and to alter the function of key viral antigens in vaccine preparations [38]. Binary ethylenimine is another alkylating agent employed for baculovirus inactivation but is suggested to preserve antigenic sites of a protein better and was therefore chosen as an alternative strategy for viral inactivation [40]. Inactivation to completeness was confirmed by the absence of viral replication and associated expression of YFP in cells upon inoculation of a volume equal to 50 vaccine doses ( $\beta \mathrm{PL}_{\text {low }} / \mathrm{BEI}_{\text {low }}$ ) into $S f 9$ cell cultures. Both inactivation protocols could preserve the hemagglutination function of the HA and VLPs were highly immunogenic at single low antigen doses. Both immunogens induced similar titers of $\mathrm{HI}$ antibodies and of total HA-specific IgGs. Immunoglobulins displayed an isotype profile indicative of a Th1-polarized response. Our serological analyses suggest that BEI-treatment of experimental influenza vaccines demonstrate a feasible alternative to $\beta P L$ inactivation.

IgG subclasses differ in their ability to induce antibody-dependent cell-mediated cytotoxicity (ADCC) and to activate the complement pathway. The Fc portion of murine IgG2a antibodies bind to activator Fc receptors and complement components with high affinity and thereby are most potently activating ADCC functions. It is of note that broadly-neutralizing anti-HA stalk antibodies with group 1 and 2 reactivity may mediate protection in an Fc $\gamma \mathrm{R}$-dependent manner and are superior inducers of ADCC as compared to anti-HA head-directed antibodies [56]. Anti-stalk antibodies bind to the membrane-proximal part of the HA and do not interfere with binding of the virus to host cells. The HI assay, a surrogate assay for the detection of neutralizing anti-HA antibodies capable of preventing virus attachment to host cells, therefore does not reveal the presence of such antibodies in sera.

In our sequential influenza-pneumococcus infection model using the vaccine non-matched influenza CAL09 challenge strain, we observed $36 \%$ and $46 \%$ survival in mice immunized with high HA-Gag VLP doses (100 ng HA). Interestingly, this protective effect was observed in the absence or with only minor induction of $\mathrm{HI}$ antibodies. However, we observed enhanced viral clearance in $\beta P L_{h i g h}$-immunized animals on day seven (two days post bacterial challenge). Similarly, in a recent report by Choi et al., vaccination with an alum-adjuvanted matched trivalent influenza vaccine at a dose of $3 \mu \mathrm{g}$ HA was able to fully protect from lethality after secondary S. aureus infection, despite not being able to elicit detectable $\mathrm{HI}$-antibodies in two-thirds of the mice and to reduce viral or bacterial replication [20]. It is tempting to speculate that the protective effect we observed was partially due to the action of broadly-neutralizing anti-stem antibodies with ADCC function.

Another unexpected finding was that mice infected with CAL09 did not demonstrate elevated pulmonary type I/II IFN expression compared to non-infected mice. We observed this effect despite high viral replication $\left(\sim 6 \log _{10} \mathrm{EID}_{50} / \mathrm{mL}\right)$ in the lungs. Differences in IFN $\alpha / \beta / \gamma$ production after influenza infection could be either a consequence of more rapid virus replication leading to a stronger stimulus for IFN expression or may be due to host- or virus-intrinsic factors. We demonstrated slower replication kinetics for CAL09 than for PR8, which is reflected by about 1.8-log lower mean pulmonary titers four days after viral infection. It is possible that this lower viral pulmonary load provided a stimulus that was below the threshold for potent innate immune activation. Evidence that supports this theory comes from our results on IFN expression in one of our PR8-infected control groups (Gag only $_{\text {) }}$.

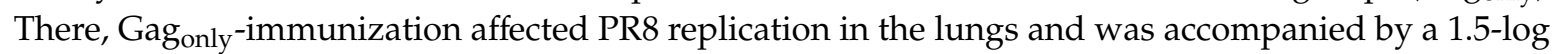
drop in viral titers on day four to a level similar to what we observed for CAL09 replication. This reduction in viral titers was sufficient to reduce IFN $\beta$ expression to basal expression levels observed in naïve, non-infected mice. The influenza NS1 protein is a virulence factor that counteracts the host innate immune response by acting as interferon-antagonist and thereby affects viral replication [57]. CAL09 (NIBRG-121xp) is a reassortant virus with internal proteins donated by PR8. The NS1 proteins of the two employed challenge viruses are therefore assumed to be similar or identical and have the same potential to inhibit interferon induction. In addition to viral ssRNA and dsRNA, carbohydrate 
moieties that decorate the virus particle were shown to mediate early host detection by C-type lectin binding [58]. In this respect, the abundance and composition of glycans on the influenza glycoproteins HA and NA may provide differential triggers for lectin-recognition and thereby affect subsequent virus aggregation, complement fixation, opsonization, phagocytosis and induction of inflammatory responses $[45,59]$. Our two challenge viruses not only display HA and NA proteins derived from two H1N1 strains isolated almost 75 years apart they also have a different history of propagation. Protein-intrinsic factors, as well as the propagation history of the viruses thereby, may contribute to the early recognition of the virus via its sugar decoration and affect its innate immune triggering capacity and replication kinetics. These findings suggest that the influenza-induced interferon signature at the time of bacterial infection cannot be used as a single read-out to estimate susceptibility of a host to secondary pneumococcal infection.

A limitation of our study was that we exclusively investigated type I/II IFN expression and did not measure other cytokines that would more specifically let us estimate the progress of secondary bacterial infections. In this respect, $\gamma \delta \mathrm{T}$ cell-mediated expression of Th17-related cytokines (i.e., IL-17A, IL-23) were demonstrated to be critical for the control of respiratory bacterial infections. Type I IFN expression was shown to affect $\gamma \delta$ T-IL-17 secretion in an IFN-dose-dependent manner, which ultimately results in the dysfunction of neutrophil recruitment and activity [9]. Interestingly, also, the influenza HA was recently demonstrated to selectively modulate innate IL-23/IL-12 and adaptive IL-17A responses to secondary pneumococcus infection and thereby constitutes an IFN-independent pathway for the inhibition of the Th17 pathway [14].

\section{Conclusions}

In summary, we studied the potential of neutralizing and non-neutralizing influenza HA-specific immunity in providing off-target protection against post-influenza pneumococcal infections. We evaluated HA-specific immunity in the context of modulating host factors (interferon type I/II expression) associated with its sensitization to secondary infection and superinfection-associated enhancement of pathogen replication, morbidity and mortality in BALB/c mice. Insect cell-expressed VLPs have proven an effective and highly immunogenic vaccine platform to allow us to investigate our research questions at convenient single, low antigen doses of 10-100 ng HA. We tested two different baculovirus inactivation methods and both, $\beta$ PL and BEI, demonstrated feasible for the inactivation of BVs in experimental influenza VLP vaccines without compromising immunogen quality and antigenicity. We presented indications that type I/II IFN responses during influenza infections may not be fully reliable markers for assessing the risk of secondary bacterial infections post-influenza. In our studies, we unexpectedly observed substantial but incomplete protection despite high HI titers induced by matching vaccine preparations, and at the same time, we demonstrated survival advantages in the absence of pre-challenge serum HI antibodies for a mismatched challenge virus. This suggests that both neutralizing and non-neutralizing immunity towards the HA may have implications in the consequences of post-influenza pneumococcal infections. HI titers, the current surrogate correlates for the prevention of influenza infections may therefore not be reliable indicators for estimating the consequences of post-influenza secondary bacterial infections. In addition, our data suggest that the nature of the vaccine vector and vaccination per se may influence the outcome of this multi-infection scenario by a mechanism termed immune training, which leaves an individual more responsive for pathogen encounters.

Supplementary Materials: The following are available online at http://www.mdpi.com/2076-393X/7/4/187/s1, Figure S1: Secondary pneumococcus infection after influenza virus infection with PR8 and CAL09 exacerbates disease and mortality in BALB/c mice.

Author Contributions: Conceptualization-M.K. and A.E.; methodology-M.K., A.E., I.A.L.; formal analysis-M.K., I.A.L., K.V.; investigation-M.K., C.L., K.V., I.N.F., N.P.K., O.A.S.; resources-I.A.L., A.V.P., M.S., R.G.; writing-original draft preparation-M.K., E.A.; writing-review and editing-M.K., I.A.L., I.N.F., K.V., A.V.P., C.L., N.P.K., O.A.S., M.S., R.G. and A.E.; visualization-M.K.; supervision-M.K., I.A.L., A.E., R.G.; project administration-M.K., A.E. and I.A.L.; funding acquisition-M.K., A.E., I.A.L. and R.G. 
Funding: This bilateral joint-project is funded by the Austrian Science Fund (FWF, grant I 3490-B30) and the Russian Science Foundation (RSF, grant 18-45-05002).

Acknowledgments: Technical support by Naune Vartanova (Department of Microbiology I. Mechnikov Research Institute for Vaccines and Sera), Makhmudova Nailya and Glubokova Ekaterina (Department of Virology I. Mechnikov Research Institute for Vaccines and Sera) is gratefully acknowledged.

Conflicts of Interest: The authors declare no conflict of interest. The funders had no role in the design of the study; in the collection, analyses, or interpretation of data; in the writing of the manuscript, or in the decision to publish the results.

\section{References}

1. Morens, D.M.; Taubenberger, J.K.; Fauci, A.S. Predominant Role of Bacterial Pneumonia as a Cause of Death in Pandemic Influenza: Implications for Pandemic Influenza Preparedness. J. Infect. Dis. 2008, 198, 962-970. [CrossRef]

2. Donkor, E.S. Understanding the pneumococcus: transmission and evolution. Front. Cell. Infect. Microbiol. 2013, 3, 7. [CrossRef]

3. Domenech de Cellès, M.; Arduin, H.; Lévy-Bruhl, D.; Georges, S.; Souty, C.; Guillemot, D.; Watier, L.; Opatowski, L. Unraveling the seasonal epidemiology of pneumococcus. Proc. Natl. Acad. Sci. USA 2019, 116, 1802-1807. [CrossRef]

4. Sharma-Chawla, N.; Sender, V.; Kershaw, O.; Gruber, A.D.; Volckmar, J.; Henriques-Normark, B.; Stegemann-Koniszewski, S.; Bruder, D. Influenza A Virus Infection Predisposes Hosts to Secondary Infection with Different Streptococcus pneumoniae Serotypes with Similar Outcome but Serotype-Specific Manifestation. Infect. Immun. 2016, 84, 3445-3457. [CrossRef]

5. Li, W.; Moltedo, B.; Moran, T.M. Type I Interferon Induction during Influenza Virus Infection Increases Susceptibility to Secondary Streptococcus pneumoniae Infection by Negative Regulation of T Cells. J. Virol. 2012, 86, 12304-12312. [CrossRef]

6. Navarini, A.A.; Recher, M.; Lang, K.S.; Georgiev, P.; Meury, S.; Bergthaler, A.; Flatz, L.; Bille, J.; Landmann, R.; Odermatt, B.; et al. Increased susceptibility to bacterial superinfection as a consequence of innate antiviral responses. Proc. Natl. Acad. Sci. USA 2006, 103, 15535-15539. [CrossRef]

7. Sun, K.; Metzger, D.W. Inhibition of pulmonary antibacterial defense by interferon- $\gamma$ during recovery from influenza infection. Nat. Med. 2008, 14, 558-564. [CrossRef]

8. Shepardson, K.M.; Larson, K.; Morton, R.V.; Prigge, J.R.; Schmidt, E.E.; Huber, V.C.; Rynda-Apple, A. Differential Type I Interferon Signaling Is a Master Regulator of Susceptibility to Postinfluenza Bacterial Superinfection. MBio 2016. [CrossRef]

9. Kudva, A.; Scheller, E.V.; Robinson, K.M.; Crowe, C.R.; Choi, S.M.; Slight, S.R.; Khader, S.A.; Dubin, P.J.; Enelow, R.I.; Kolls, J.K.; et al. Influenza A Inhibits Th17-Mediated Host Defense against Bacterial Pneumonia in Mice. J. Immunol. 2011, 186, 1666-1674. [CrossRef]

10. Smith, A.M.; Adler, F.R.; Ribeiro, R.M.; Gutenkunst, R.N.; McAuley, J.L.; McCullers, J.A.; Perelson, A.S. Kinetics of Coinfection with Influenza A Virus and Streptococcus pneumoniae. PLoS Pathog. 2013, 9, e1003238. [CrossRef]

11. Ghoneim, H.E.; Thomas, P.G.; McCullers, J.A. Depletion of Alveolar Macrophages during Influenza Infection Facilitates Bacterial Superinfections. J. Immunol. 2013, 191, 1250-1259. [CrossRef]

12. McNamee, L.A.; Harmsen, A.G. Both Influenza-Induced Neutrophil Dysfunction and Neutrophil-Independent Mechanisms Contribute to Increased Susceptibility to a Secondary Streptococcus pneumoniae Infection. Infect. Immuny 2006, 74, 6707-6721. [CrossRef]

13. Small, C.-L.; Shaler, C.R.; McCormick, S.; Jeyanathan, M.; Damjanovic, D.; Brown, E.G.; Arck, P.; Jordana, M.; Kaushic, C.; Ashkar, A.A.; et al. Influenza Infection Leads to Increased Susceptibility to Subsequent Bacterial Superinfection by Impairing NK Cell Responses in the Lung. J. Immunol. 2010, 184, 2048-2056. [CrossRef]

14. Loughran, S.T.; Power, P.A.; Maguire, P.T.; McQuaid, S.L.; Buchanan, P.J.; Jonsdottir, I.; Newman, R.W.; Harvey, R.; Johnson, P.A. Influenza infection directly alters innate IL-23 and IL-12p70 and subsequent IL-17A and IFN- $\gamma$ responses to pneumococcus in vitro in human monocytes. PLOS ONE 2018, 13, e0203521. [CrossRef] 
15. Mina, M.J.; Klugman, K.P.; McCullers, J.A. Live Attenuated Influenza Vaccine, But Not Pneumococcal Conjugate Vaccine, Protects Against Increased Density and Duration of Pneumococcal Carriage After Influenza Infection in Pneumococcal Colonized Mice. J. Infect. Dis. 2013, 208, 1281-1285. [CrossRef]

16. Song, J.Y.; Lee, J.S.; Wie, S.-H.; Kim, H.Y.; Lee, J.; Seo, Y.B.; Jeong, H.W.; Kim, S.W.; Lee, S.H.; Park, K.-H.; et al. Prospective Cohort Study on the Effectiveness of Influenza and Pneumococcal Vaccines in Preventing Pneumonia Development and Hospitalization. Clin. Vaccine Immunol. 2015, 22, 229-234. [CrossRef]

17. Daniels, C.C.; Rogers, P.D.; Shelton, C.M. A Review of Pneumococcal Vaccines: Current Polysaccharide Vaccine Recommendations and Future Protein Antigens. J. Pediatr. Pharmacol. Ther. 2016, 21, 27-35. [CrossRef]

18. Ladhani, S.N.; Collins, S.; Djennad, A.; Sheppard, C.L.; Borrow, R.; Fry, N.K.; Andrews, N.J.; Miller, E.; Ramsay, M.E. Rapid increase in non-vaccine serotypes causing invasive pneumococcal disease in England and Wales, 2000-17: a prospective national observational cohort study. Lancet Infect. Dis. 2018, 18, 441-451. [CrossRef]

19. Heikkinen, T.; Block, S.L.; Toback, S.L.; Wu, X.; Ambrose, C.S. Effectiveness of Intranasal Live Attenuated Influenza Vaccine Against All-cause Acute Otitis Media in Children. Pediatr. Infect. Dis. J. 2013, 32, 669-674. [CrossRef]

20. Choi, A.; Christopoulou, I.; Saelens, X.; García-Sastre, A.; Schotsaert, M. TIV Vaccination Modulates Host Responses to Influenza Virus Infection that Correlate with Protection against Bacterial Superinfection. Vaccines 2019, 7, 113. [CrossRef]

21. Huber, V.C.; Peltola, V.; Iverson, A.R.; McCullers, J.A. Contribution of Vaccine-Induced Immunity toward either the HA or the NA Component of Influenza Viruses Limits Secondary Bacterial Complications. J. Virol. 2010, 84, 4105-4108. [CrossRef]

22. Klausberger, M.; Leneva, I.A.; Egorov, A.; Strobl, F.; Ghorbanpour, S.M.; Falynskova, I.N.; Poddubikov, A.V.; Makhmudova, N.R.; Krokhin, A.; Svitich, O.A.; et al. Off-target effects of an insect cell-expressed influenza HA-pseudotyped Gag-VLP preparation in limiting postinfluenza Staphylococcus aureus infections. Vaccine 2019, in press. [CrossRef]

23. Flannery, B.; Zimmerman, R.K.; Gubareva, L.V.; Garten, R.J.; Chung, J.R.; Nowalk, M.P.; Jackson, M.L.; Jackson, L.A.; Monto, A.S.; Ohmit, S.E.; et al. Enhanced Genetic Characterization of Influenza A(H3N2) Viruses and Vaccine Effectiveness by Genetic Group, 2014-2015. J. Infect. Dis. 2016, 214, 1010-1019. [CrossRef]

24. Jacobsen, H.; Rajendran, M.; Choi, A.; Sjursen, H.; Brokstad, K.A.; Cox, R.J.; Palese, P.; Krammer, F.; Nachbagauer, R. Influenza Virus Hemagglutinin Stalk-Specific Antibodies in Human Serum are a Surrogate Marker for In Vivo Protection in a Serum Transfer Mouse Challenge Model. mBio 2017, 8. [CrossRef]

25. Krammer, F.; Margine, I.; Hai, R.; Flood, A.; Hirsh, A.; Tsvetnitsky, V.; Chen, D.; Palese, P. H3 stalk-based chimeric hemagglutinin influenza virus constructs protect mice from H7N9 challenge. J. Virol. 2014, 88, 2340-2343. [CrossRef]

26. Klausberger, M.; Tscheliessnig, R.; Neff, S.; Nachbagauer, R.; Wohlbold, T.J.; Wilde, M.; Palmberger, D.; Krammer, F.; Jungbauer, A.; Grabherr, R. Globular Head-Displayed Conserved Influenza H1 Hemagglutinin Stalk Epitopes Confer Protection against Heterologous H1N1 Virus. PLoS ONE 2016, 11, e0153579. [CrossRef]

27. Shrestha, A.; Bao, K.; Chen, Y.-R.; Chen, W.; Wang, P.; Fei, Z.; Blissard, G.W. Global Analysis of Baculovirus Autographa californica Multiple Nucleopolyhedrovirus Gene Expression in the Midgut of the Lepidopteran Host Trichoplusia ni. J. Virol. 2018, 92. [CrossRef]

28. Reed, L.J.; Muench, H. A Simple Method of Estimating Fifty Per Cent Endpoints12. Am. J. Epidemiol. 1938, 27, 493-497. [CrossRef]

29. Reiter, K.; Aguilar, P.P.; Wetter, V.; Steppert, P.; Tover, A.; Jungbauer, A. Separation of virus-like particles and extracellular vesicles by flow-through and heparin affinity chromatography. J. Chromatogr. A 2019, 1588, 77-84. [CrossRef]

30. Krammer, F.; Margine, I.; Tan, G.S.; Pica, N.; Krause, J.C.; Palese, P. A Carboxy-Terminal Trimerization Domain Stabilizes Conformational Epitopes on the Stalk Domain of Soluble Recombinant Hemagglutinin Substrates. PLoS ONE 2012, 7, e43603. [CrossRef]

31. Klausberger, M.; Wilde, M.; Palmberger, D.; Hai, R.; Albrecht, R.A.; Margine, I.; Hirsh, A.; García-Sastre, A.; Grabherr, R.; Krammer, F. One-shot vaccination with an insect cell-derived low-dose influenza A H7 virus-like particle preparation protects mice against H7N9 challenge. Vaccine 2014, 32, 355-362. [CrossRef] 
32. Bright, R.A.; Carter, D.M.; Daniluk, S.; Toapanta, F.R.; Ahmad, A.; Gavrilov, V.; Massare, M.; Pushko, P.; Mytle, N.; Rowe, T.; et al. Influenza virus-like particles elicit broader immune responses than whole virion inactivated influenza virus or recombinant hemagglutinin. Vaccine 2007, 25, 3871-3878. [CrossRef]

33. Schmidt, S.T.; Khadke, S.; Korsholm, K.S.; Perrie, Y.; Rades, T.; Andersen, P.; Foged, C.; Christensen, D. The administration route is decisive for the ability of the vaccine adjuvant CAF09 to induce antigen-specific CD8 + T-cell responses: The immunological consequences of the biodistribution profile. J. Control. Release 2016, 239, 107-117. [CrossRef]

34. Shahangian, A.; Chow, E.K.; Tian, X.; Kang, J.R.; Ghaffari, A.; Liu, S.Y.; Belperio, J.A.; Cheng, G.; Deng, J.C. Type I IFNs mediate development of postinfluenza bacterial pneumonia in mice. J. Clin. Investig. 2009, 119, 1910-1920. [CrossRef]

35. McCullers, J.A.; Rehg, J.E. Lethal Synergism between Influenza Virus and Streptococcus pneumoniae: Characterization of a Mouse Model and the Role of Platelet-Activating Factor Receptor. J. Infect. Dis. 2002, 186, 341-350. [CrossRef]

36. Pushko, P.; Tretyakova, I.; Hidajat, R.; Sun, X.; Belser, J.A.; Tumpey, T.M. Multi-clade H5N1 virus-like particles: Immunogenicity and protection against $\mathrm{H} 5 \mathrm{~N} 1$ virus and effects of beta-propiolactone. Vaccine 2018, 36, 4346-4353. [CrossRef]

37. Rueda, P.; Fominaya, J.; Langeveld, J.P.; Bruschke, C.; Vela, C.; Casal, J.I. Effect of different baculovirus inactivation procedures on the integrity and immunogenicity of porcine parvovirus-like particles. Vaccine 2000, 19, 726-734. [CrossRef]

38. She, Y.-M.; Cheng, K.; Farnsworth, A.; Li, X.; Cyr, T.D. Surface modifications of influenza proteins upon virus inactivation by $\beta$-propiolactone. PROTEOMICS 2013, 13, 3537-3547. [CrossRef]

39. Herrera-Rodriguez, J.; Signorazzi, A.; Holtrop, M.; de Vries-Idema, J.; Huckriede, A. Inactivated or damaged? Comparing the effect of inactivation methods on influenza virions to optimize vaccine production. Vaccine 2019, 37, 1630-1637. [CrossRef]

40. Blackburn, N.K.; Besselaar, T.G. A study of the effect of chemical inactivants on the epitopes of Rift Valley fever virus glycoproteins using monoclonal antibodies. J. Virol. Methods 1991, 33, 367-374. [CrossRef]

41. Hervas-Stubbs, S.; Rueda, P.; Lopez, L.; Leclerc, C. Insect Baculoviruses Strongly Potentiate Adaptive Immune Responses by Inducing Type I IFN. J. Immunol. 2007, 178, 2361-2369. [CrossRef]

42. Suzuki, T.; Chang, M.O.; Kitajima, M.; Takaku, H. Baculovirus activates murine dendritic cells and induces non-specific NK cell and T cell immune responses. Cell. Immunol. 2010, 262, 35-43. [CrossRef]

43. Heinimäki, S.; Tamminen, K.; Malm, M.; Vesikari, T.; Blazevic, V. Live baculovirus acts as a strong B and T cell adjuvant for monomeric and oligomeric protein antigens. Virology 2017, 511, 114-122. [CrossRef]

44. Margine, I.; Martinez-Gil, L.; Chou, Y.-Y.; Krammer, F. Residual baculovirus in insect cell-derived influenza virus-like particle preparations enhances immunogenicity. PLoS ONE 2012, 7, e51559. [CrossRef]

45. Klonoski, J.M.; Watson, T.; Bickett, T.E.; Svendsen, J.M.; Gau, T.J.; Britt, A.; Nelson, J.T.; Schlenker, E.H.; Chaussee, M.S.; Rynda-Apple, A.; et al. Contributions of Influenza Virus Hemagglutinin and Host Immune Responses Toward the Severity of Influenza Virus: Streptococcus pyogenes Superinfections. Viral Immunol. 2018, 31, 457-469. [CrossRef]

46. Lee, B.; Robinson, K.M.; McHugh, K.J.; Scheller, E.V.; Mandalapu, S.; Chen, C.; Di, Y.P.; Clay, M.E.; Enelow, R.I.; Dubin, P.J.; et al. Influenza-induced type I interferon enhances susceptibility to gram-negative and gram-positive bacterial pneumonia in mice. Am. J. Physiol. Lung Cell Mol. Physiol. 2015, 309, L158-L167. [CrossRef]

47. McCullers, J.A.; Bartmess, K.C. Role of neuraminidase in lethal synergism between influenza virus and Streptococcus pneumoniae. J. Infect. Dis. 2003, 187, 1000-1009. [CrossRef]

48. Sareneva, T.; Matikainen, S.; Kurimoto, M.; Julkunen, I. Influenza A virus-induced IFN-alpha/beta and IL-18 synergistically enhance IFN-gamma gene expression in human T cells. J. Immunol. 1998, 160, 6032-6038.

49. Price, G.E.; Gaszewska-Mastarlarz, A.; Moskophidis, D. The role of alpha/beta and gamma interferons in development of immunity to influenza A virus in mice. J. Virol. 2000, 74, 3996-4003. [CrossRef]

50. Abe, T.; Hemmi, H.; Miyamoto, H.; Moriishi, K.; Tamura, S.; Takaku, H.; Akira, S.; Matsuura, Y. Involvement of the Toll-Like Receptor 9 Signaling Pathway in the Induction of Innate Immunity by Baculovirus. J. Virol. 2005, 79, 2847-2858. [CrossRef]

51. Moriyama, T.; Suzuki, T.; Chang, M.O.; Kitajima, M.; Takaku, H. Baculovirus directly activates murine NK cells via TLR9. Cancer Gene. Ther. 2017, 24, 175-179. [CrossRef] 
52. Cooper, M.A.; Elliott, J.M.; Keyel, P.A.; Yang, L.; Carrero, J.A.; Yokoyama, W.M. Cytokine-induced memory-like natural killer cells. Proc. Natl. Acad. Sci. USA 2009, 106, 1915-1919. [CrossRef]

53. Norton, E.B.; Clements, J.D.; Voss, T.G.; Cardenas-Freytag, L. Prophylactic Administration of Bacterially Derived Immunomodulators Improves the Outcome of Influenza Virus Infection in a Murine Model. J. Virol. 2010, 84, 2983-2995. [CrossRef]

54. Uittenbogaard, J.P.; Zomer, B.; Hoogerhout, P.; Metz, B. Reactions of $\beta$-Propiolactone with Nucleobase Analogues, Nucleosides, and Peptides: Implications for The Inactivation of Viruses. J. Biol. Chem. 2011, 286, 36198-36214. [CrossRef]

55. Delrue, I.; Verzele, D.; Madder, A.; Nauwynck, H.J. Inactivated virus vaccines from chemistry to prophylaxis: merits, risks and challenges. Expert Rev. Vaccines 2012, 11, 695-719. [CrossRef]

56. DiLillo, D.J.; Tan, G.S.; Palese, P.; Ravetch, J.V. Broadly neutralizing hemagglutinin stalk-specific antibodies require Fc $\gamma \mathrm{R}$ interactions for protection against influenza virus in vivo. Nat. Med. 2014, 20, 143-151. [CrossRef]

57. Petersen, H.; Mostafa, A.; Tantawy, M.A.; Iqbal, A.A.; Hoffmann, D.; Tallam, A.; Selvakumar, B.; Pessler, F.; Beer, M.; Rautenschlein, S.; et al. NS Segment of a 1918 Influenza A Virus-Descendent Enhances Replication of H1N1pdm09 and Virus-Induced Cellular Immune Response in Mammalian and Avian Systems. Front. Microbiol. 2018, 9, 526. [CrossRef]

58. Reading, P.C.; Tate, M.D.; Pickett, D.L.; Brooks, A.G. Glycosylation as a Target for Recognition of Influenza Viruses by the Innate Immune System. In Current Topics in Innate Immunity; Lambris, J.D., Ed.; Springer: New York, NY, USA, 2007; Volume 598, pp. 279-292. ISBN 978-0-387-71765-4.

59. Sun, X.; Jayaraman, A.; Maniprasad, P.; Raman, R.; Houser, K.V.; Pappas, C.; Zeng, H.; Sasisekharan, R.; Katz, J.M.; Tumpey, T.M. N-Linked Glycosylation of the Hemagglutinin Protein Influences Virulence and Antigenicity of the 1918 Pandemic and Seasonal H1N1 Influenza A Viruses. J. Virol. 2013, 87, 8756-8766. [CrossRef]

(C) 2019 by the authors. Licensee MDPI, Basel, Switzerland. This article is an open access article distributed under the terms and conditions of the Creative Commons Attribution (CC BY) license (http://creativecommons.org/licenses/by/4.0/). 